\title{
Controllable fabrication and multifunctional applications of graphene/ceramic composites
}

\author{
Yujia HUANG, Chunlei WAN* \\ State Key Lab of New Ceramics and Fine Processing, School of Materials Science and \\ Engineering, Tsinghua University, Beijing 100084, China
}

Received: January 3, 2020; Revised: February 29, 2020; Accepted: March 18, 2020

(C) The Author(s) 2020.

\begin{abstract}
Graphene with excellent comprehensive properties has been considered as a promising filler to reinforce ceramics. While numerous studies have been devoted to the improvement of mechanical and electrical properties, incorporating graphene to ceramics also offers new opportunities for endowing ceramics with versatility. In this review, the recent development of graphene/ceramic bulk composites is summarized with the focus on the construction of well-designed architecture and the realization of multifunctional applications. The processing technologies of the composites are systematically summarized towards homogeneous dispersion and even ordered orientation of graphene sheets in the ceramic matrix. The improvement of composites in mechanical, electrical, electromagnetic, and thermal performances is discussed. The novel multifunctional applications brought by smart integration of graphene in ceramics are also addressed, including microwave absorption, electromagnetic interference shielding, ballistic armors, self-monitor damage sensors, and energy storage and conversion.
\end{abstract}

Keywords: graphene/ceramic composites; synthesis; mechanical property; electromagnetic properties; thermal properties; multifunction

\section{Introduction}

Monolithic ceramics feature at high stiffness, high melting point, high thermal stability, and wear resistance, but are restricted by the low fracture toughness and poor electrical conductivity for further applications. Introduction of fillers into the ceramic matrix becomes an effective strategy to solve these issues [1-3]. As one representative two-dimensional (2D) material, graphene is a promising filler because of its outstanding properties, such as excellent mechanical properties [4], high electrical conductivity [5,6], high thermal conductivity [7], etc.

\footnotetext{
* Corresponding author.

E-mail: wancl@mail.tsinghua.edu.cn
}

By adding only $1.5 \mathrm{vol} \%$ graphene, the fracture toughness of $\mathrm{Si}_{3} \mathrm{~N}_{4}$ increased from 2.8 to $6.6 \mathrm{MPa} \cdot \mathrm{m}^{1 / 2}(235 \%)$ with toughening mechanisms including graphene sheets pull-out, crack bridging, and crack deflection [8]. Due to better distribution of graphene and better contact between the conductive sheets, the electrical conductivity of graphene $/ \mathrm{Al}_{2} \mathrm{O}_{3}$ composites can achieve $10^{3} \mathrm{~S} / \mathrm{m}$ with only $2.35 \mathrm{vol} \%$ graphene [9], while carbon nanotube (CNT) content should be as high as 5.7 vol\% to reach the same level of conductivity in the $\mathrm{CNT} / \mathrm{Al}_{2} \mathrm{O}_{3}$ composites [10], showing great advantage of graphene as the filler in ceramic composites.

In addition to the enhancement of mechanical properties or electrical conductivity in the graphene/ ceramic composites, graphene with various characteristics such as $2 \mathrm{D}$ structural characteristics [11] also provides 
possibilities for the synthesis of composites exhibiting unique versatilities. For example, the anisotropic electrical and thermal conductivity of the graphene/ $\mathrm{SrTiO}_{3}$-based composites was realized by the alignment of the oriented 2D graphene sheets, which enabled further explorations in the thermoelectric performance [12]. Also, by building the texture of highly conductive graphene sheets in the SiC-based composites, a high value of electromagnetic interference shielding effectiveness over $40 \mathrm{~dB}$ in the Ku-band was attained with a load of only $3 \mathrm{wt} \%$ graphene [13]. The higher electrical conductivity of the composites, the formation of mini-capacitors and multiple reflections between oriented graphene sheets contributed to this high value.

To better realize the multiple functions in the graphene/ceramic composites, it is strongly required to form a carefully designed microstructure in the graphene/ceramic composites, in which the choice of raw materials and processing technologies directly affects the microstructure and finally determines the performances. Critical issues such as homogeneous dispersion and orientation of graphene in the ceramic matrix and interfacial interaction between graphene and the ceramic matrix have arisen, severely limiting the multifunctional applications of the composites.

Based on these issues, here we try to give a comprehensive understanding of the controlled fabrication and multifunctional applications of graphene/ ceramic bulk composites. Firstly, the preparation and characteristics of graphene sources are presented. Then, the powder synthesis and ceramic sintering technologies of graphene/ceramic composites are described. The effects of graphene on mechanical, electrical, electromagnetic, and thermal properties of graphene/ ceramic bulk composites are discussed. The novel versatile applications such as microwave absorption, electromagnetic interference shielding, ballistic armors, self-monitor damage sensors, and energy storage and conversion applications are also introduced. The topics of this review are outlined in Fig. 1.

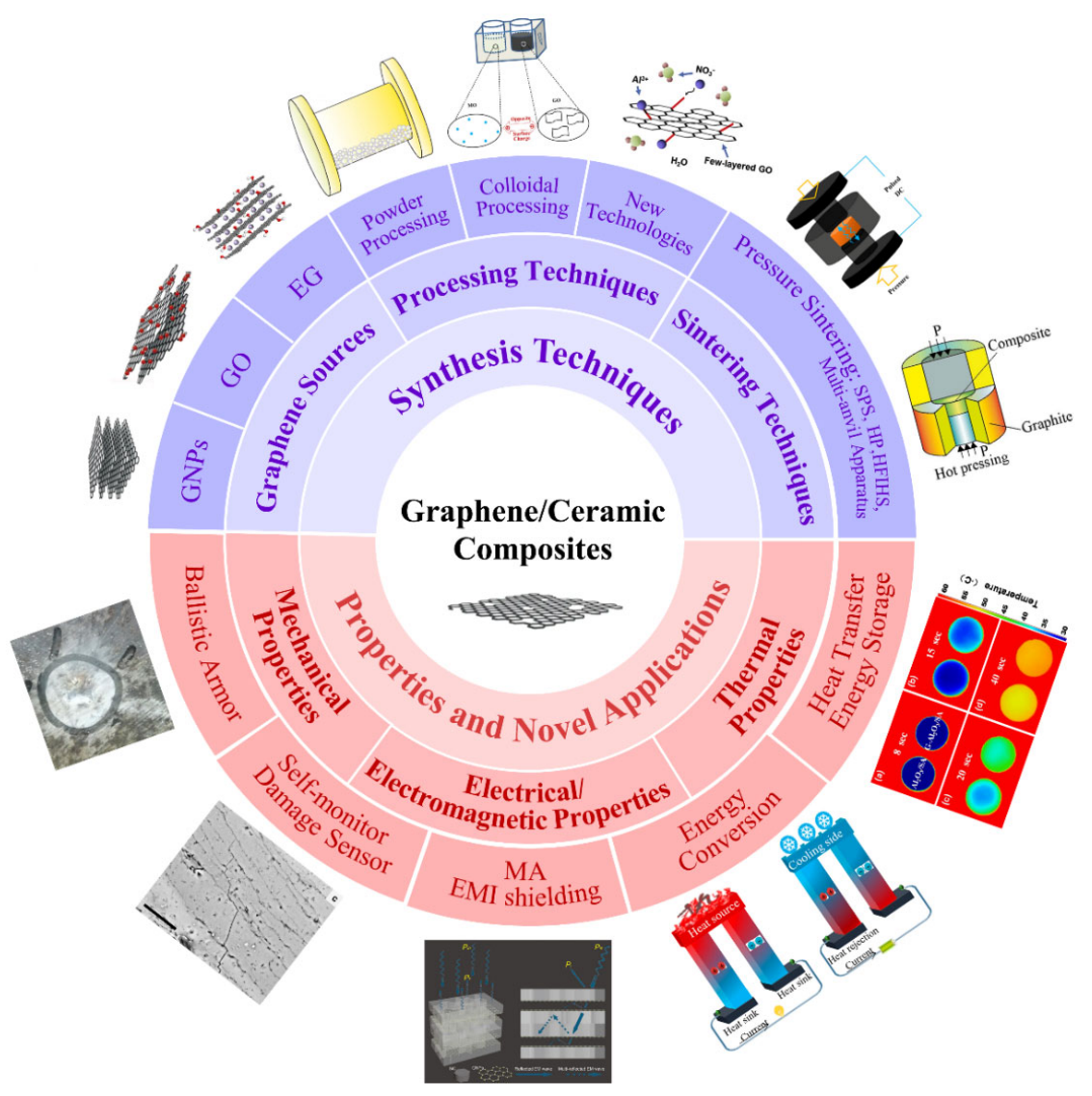

Fig. 1 Schematic of the topics covered in this review. Summary of the synthesis, properties, and applications of graphene/ceramic composites. Reproduced with permission from Ref. [6], (C) Springer Nature 2014; Ref. [13], (C) Elsevier Ltd. 2018; Ref. [14], (C) Springer Nature 2017; Ref. [15], (C) Elsevier Ltd and Techna Group S.r.1. 2017; Ref. [16], (C Elsevier Ltd. 2014; Ref. [17], (C) Elsevier Ltd. 2014; Ref. [18], (C) Elsevier Ltd and Techna Group S.r.l. 2019; Ref. [19], (C) Elsevier Ltd. 2014; Ref. [20], (C) The Author(s) 2019; Ref. [21], (C) Springer Nature 2014. 


\section{Controllable fabrication of the graphene/ ceramic composites}

In the fabrication of the graphene/ceramic composites, the graphene sources, the powder processing techniques, and the sintering techniques are the three key aspects that determine the retention of superior characteristics of graphene as well as the control of the uniform distribution of graphene in the ceramic matrix and the realization of special structure such as network or preferred orientation.

\section{1 Synthesis and characteristics of the graphene sources}

The selection of graphene sources is particularly important in consideration of the intrinsic properties of graphene, the homogenous dispersion of graphene, and the interaction between graphene and ceramics in the composites. Therefore, the carbon materials that can be either directly used or be transformed into graphene layers are briefly introduced in this section. According to Refs. [22,23], the number of graphene layers, the lateral dimensions, and the degrees of oxidation are three key parameters to classify the $2 \mathrm{D}$ carbon materials. Graphene or monolayer graphene is one-atom-thick material with hexagonal arranged, $\mathrm{sp}^{2}$-bonded carbon atoms. Few-layer graphene (FLG) consists of 2-5 layers of graphene and multi-layer graphene (MLG) contains 5-10 layers. Graphite nanoplates (GNPs), graphite nanoplatelets (GPLs), or graphite nanosheets (GNSs) consist of more than 10 layers but their thickness/lateral dimension is less than $100 \mathrm{~nm}$. For easy understanding, GNPs are adopted here, representing graphene-type derivatives with no or low oxygen content. Graphene oxide (GO) or expanded graphite (EG) can be produced from graphite oxide with different oxidation levels.

Normal synthesis methods of GNPs contain mechanical exfoliation, liquid-phase exfoliation, chemical vapor deposition (CVD), and reduction of GO. Mechanical exfoliation typically refers to ball milling or repeated peeling of graphite by tape [24]. The tape method is time-consuming with low yield, while it is possible to realize mass production by the ball milling method. Liquid-phase exfoliation (Fig. 2(a)) is a facile and economical technology that enables mass production of high-quality graphene. The parameters of ultrasonication should be controlled to exfoliate the graphene sheets and retain the lateral size of graphene [26]. To remove (a)
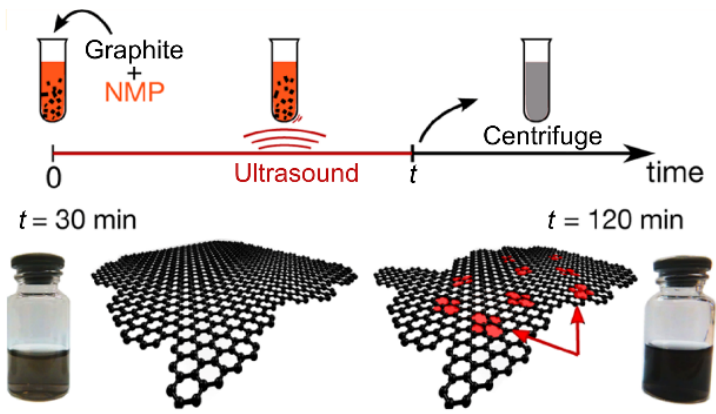

(b)

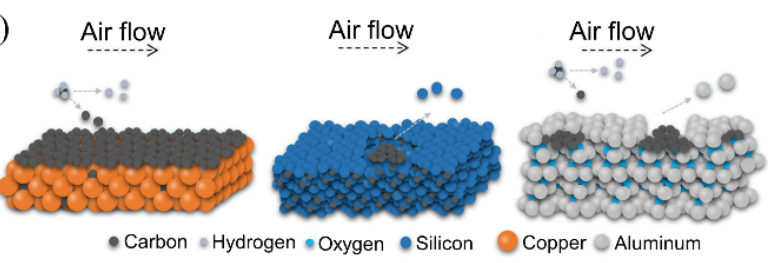

Fig. 2 Illustration of synthesis methods of GNPs. (a) Liquid-phase exfoliation technologies and defect localization depends on the sonication time. Reproduced with permission from Ref. [25], (C) American Chemical Society 2014. (b) CVD graphene growth on different substrate surfaces. Reproduced with permission from Ref. [28], (c) The Royal Society of Chemistry 2017.

un-exfoliated graphite for the further purification, graphene dispersion liquid is centrifuged at $\sim 500 \mathrm{rpm}$ [25] and the supernatant is collected. The dispersion agent can be changed by the filtration, wash, and re-dispersion in another solvent [27]. The CVD process (Fig. 2(b)) enables the production of large-area graphene with good quality, but the expensive cost limits the applications in composites production. Despite the high cost, GNPs with fewer structural defects and outstanding intrinsic properties are widely used in ceramic composites. To avoid agglomerations caused by the high specific surface area and van der Waals interaction [23], surface modification such as oxidation (GO) is an efficient strategy. The reduction of GO [29] is another effective and economical method to produce GNPs or reduced graphene oxide (rGO).

Oxygen functional groups, including hydroxyl, epoxy, carbonyl, and carboxyl groups, can be introduced by the intercalation and oxidation of graphite with strong acid and oxidant [30-32] such as potassium permanganate and concentrated sulfuric acid [33]. The functional groups also bring strong hydrophilicity, so GO can be well dispersed and form monolayers or few-layer nanosheets in water or other organic solvents by stirring or ultrasonication [30]. Then ceramic powder or slurry is added into the GO dispersion and mixed homogeneously by ultrasonication. First obtaining rGO and then mixing 
it with ceramics belongs to the cases [34,35] with GNPs as the graphene sources. Usually, for better dispersion, reduction of GO can be conducted after mixing, by reducing agents such as hydrazine [36] or heating in the calcination or sintering process [37]. The residual functional groups, defects, and layers of rGO can be further characterized by X-ray photoelectron spectroscopy (XPS), Fourier transform infrared spectroscopy (FTIR) [38] or Raman spectroscopy, as illustrated in Fig. 3. Although residual functional groups, defects caused by oxidation and the wrinkled nature of rGO may damage its excellent intrinsic properties, the interaction between rGO and metal oxide is stronger than that between GNPs and metal oxide $[42,43]$. In addition, the low economic cost makes GO a promising graphene source.

Expanded graphite (EG) is produced from rapid heat treatment of expandable graphite, which is also prepared by intercalation of strong concentrated sulfuric acid and nitric acid into graphite with lower oxidation degrees [44]. Along with release of the intercalants at high temperature or microwave treatment, the interlayer spacing of graphite increases by 10-100 times along the $c$-direction [45], providing space for ceramic accommodation. The final thickness of the graphene sheets from EG in composites is relatively large
$(10-100 \mathrm{~nm})[45,46]$, but the very low cost of EG offers great potential in practical applications.

\section{2 Processing technologies of the composite powder}

Generally, processing technologies of the composite powder include powder processing, colloidal processing, and new technologies such as polymer-derived technologies.

Powder processing typically refers to the simple process of mixing graphene sheets and ceramic powders by ball milling with a dispersion agent such as ethanol $[13,47]$ and isopropanol $[48,49]$. A typical procedure is illustrated in Fig. 4(a). During ball milling, agglomerations of graphene sheets can be somewhat avoided due to shear stress with relative homogenous dispersion of graphene in the ceramic matrix. However, the agglomeration cannot be fully removed and the thickness of the graphene layers are always too large. During the subsequent sintering process, pores may be formed due to the weak interfacial bonding between graphene and the ceramic matrix [50]. In general powder processing is still a facile method that enables large-scale production of the graphene/ceramic composites.
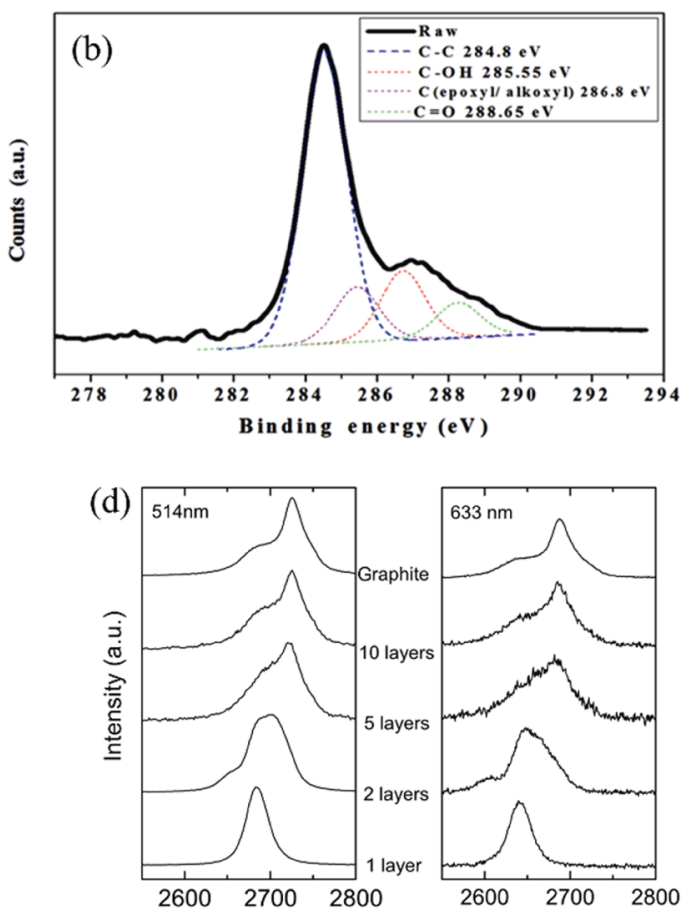

Fig. 3 X-ray photoelectron spectra of (a) GO and (b) rGO. Reproduced with permission from Ref. [39], (C) Springer-Verlag 2011. (c) Raman spectra of graphite, GO, and functionalized single graphene sheets (FGS). Reproduced with permission from Ref. [40], (c) American Chemical Society 2008. (d) Evolution of the Raman spectra at 514 and $633 \mathrm{~nm}$ respectively with the number of graphene layers. Reproduced with permission from Ref. [41], (c) The American Physical Society 2006. 
(a)

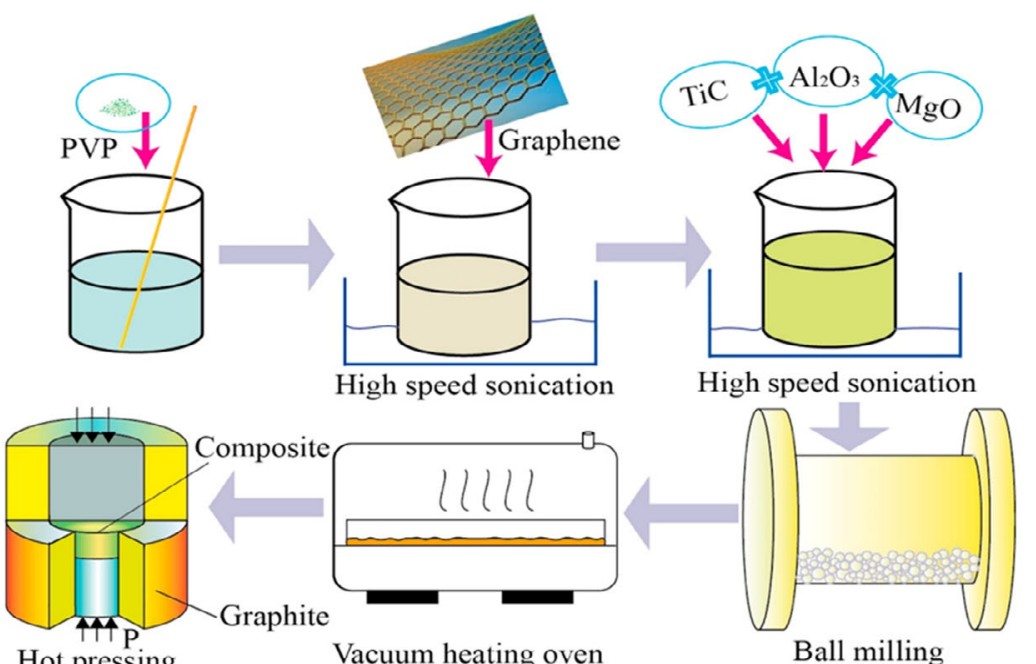

(b) Sonication
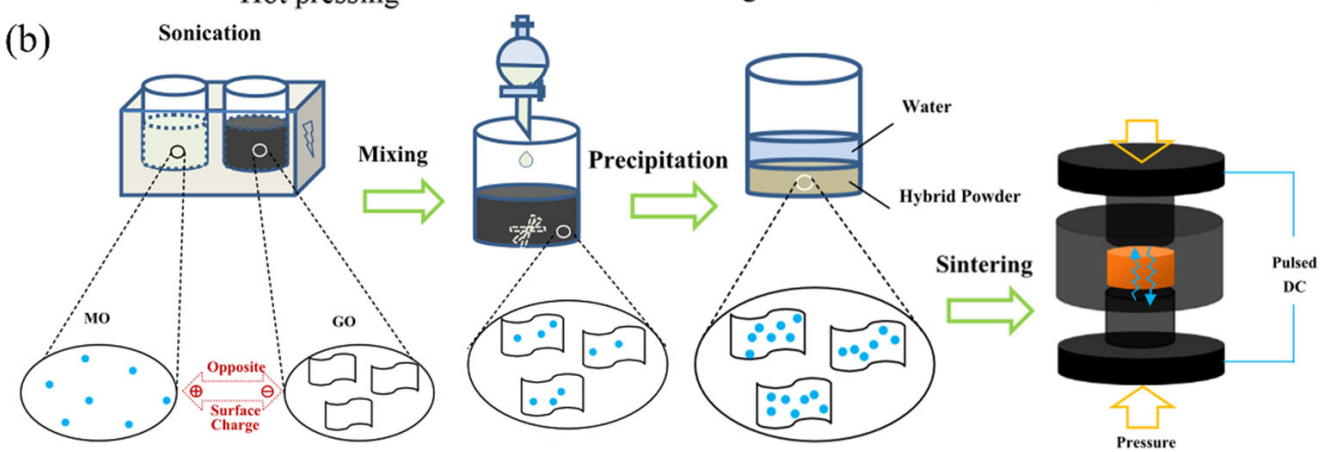

(c)
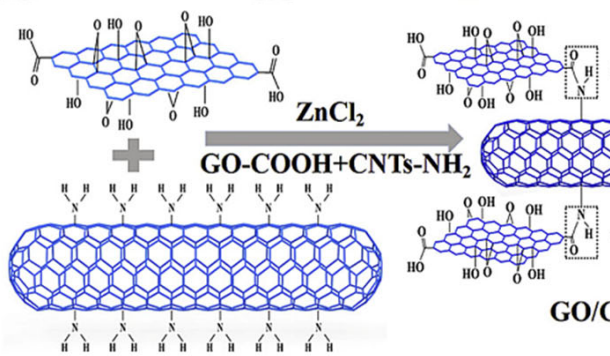

Hо $\mathrm{O}$ 응

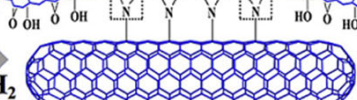

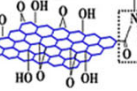
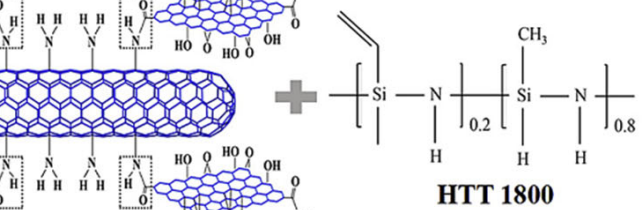

HTT 1800

GO/CNTs hybrids
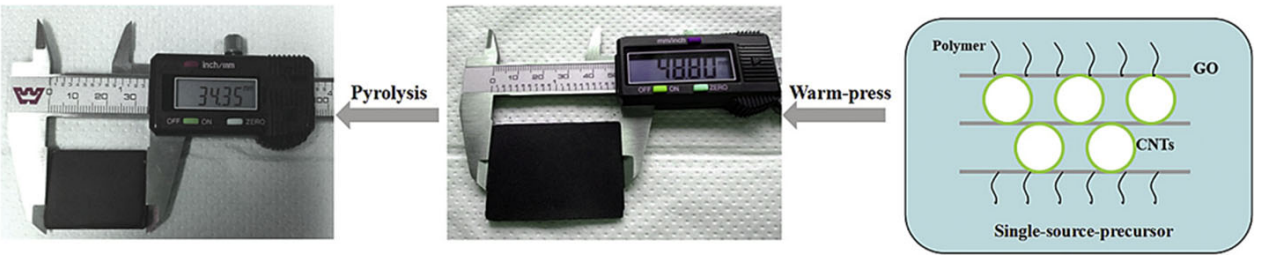

(d)
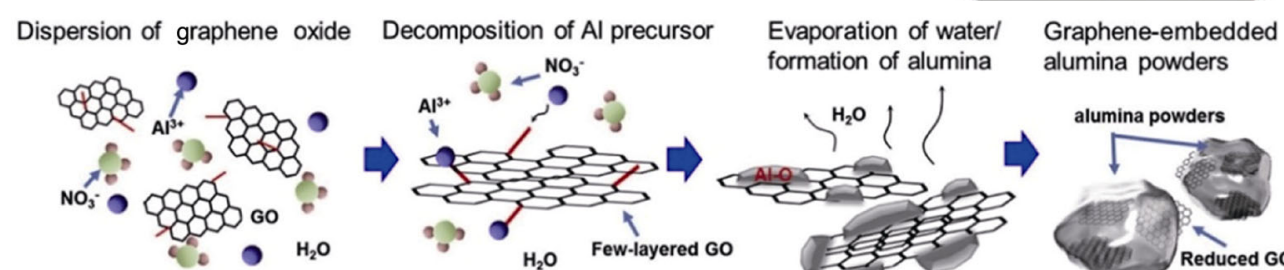
formation of alumina alumina powders
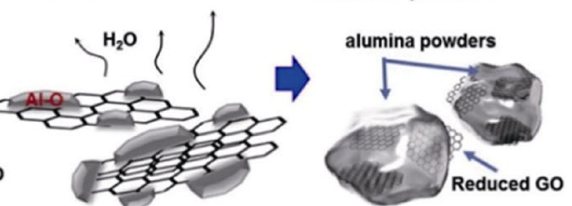

Fig. 4 Illustration of processing technologies of the graphene/ceramic composites. (a) Fabrication process (ball milling) of multilayer graphene (MLG) $/ \mathrm{Al}_{2} \mathrm{O}_{3} / \mathrm{TiC}$ ceramic tool material. Reproduced with permission from Ref. [15], (C) Elsevier Ltd and Techna Group S.r.l. 2017. (b) Fabrication process of FLG/ MO nanocomposite by hetero-aggregation of colloids. Reproduced with permission from Ref. [16], (C) Elsevier Ltd. 2014. (c) Fabrication process of rGO/CNTs-SiCN nanocomposites from polymer precursor. Reproduced with permission from Ref. [60], (C) Acta Materialia Inc. 2017. (d) Fabrication process of rGO/alumina composite powders by molecular level mixing process. Reproduced with permission from Ref. [17], (C) Elsevier Ltd. 2014. 
Colloidal processing is a technique whereby graphene sheets and ceramic powders are dissolved and mixed in similar solvents to form colloidal suspensions. Surface modification is particularly important for graphene and ceramics to generate opposite charges for stable dispersion. Using the hetero-aggregation method, Fan et al. $[9,16,51,52]$ achieved homogeneous mixing of a GO colloid and an $\mathrm{Al}_{2} \mathrm{O}_{3}$ colloid with opposite zeta potentials, as illustrated in Fig. 4(b). With the heterogeneous co-precipitation reaction initiator, cetyltrimethylammonium bromide (CTAB), GO sheets were uniformly dispersed among CTAB-coated $\mathrm{B}_{4} \mathrm{C}$ particles through electrostatic attraction [53]. To form a crosslinked network structure of $\mathrm{GO}$ in the $\mathrm{GO} / \mathrm{B}_{4} \mathrm{C}$ composite powders, Hu et al. [54] adopted a self-assembly polymerization process induced by polymerization of acrylamide monomer. In the composites fabricated by colloidal processing, graphene sheets are thin and uniformly distributed, but the complex surface modification techniques are required to build delicate architectures such as network or preferred orientation of graphene in the ceramic matrix.

To achieve more uniform dispersion or special structures, new technologies using ceramic precursors, especially polymer precursors [14,55-61] are developed. As illustrated in Fig. 4(c), GO/CNTs hybrids were first synthesized by amidation reaction with $\mathrm{ZnCl}_{2}$ as the catalyst and then mixed with polysilazane HTT 1800 (precursor for $\mathrm{SiCN}$ ) by magnetic stirring. After crosslinking, ball milling, warm-press, and pyrolysis of the as-prepared GO/CNTs-HTT 1800 single-source-precursor, the network structure (with the width of $80-100 \mathrm{~nm}$ ) of carbon nanofillers was in situ formed in the final rGO/CNTs-SiCN bulk composites. Inorganic precursors can also be applied in the fabrication of the composites. Lee et al. [17] successfully mixed $\mathrm{GO}$ and the $\mathrm{Al}$ ion from $\mathrm{Al}\left(\mathrm{NO}_{3}\right)_{3} \cdot 9 \mathrm{H}_{2} \mathrm{O}$ at the molecular level (Fig. 4(d)) and created strong interfacial $\mathrm{Al}-\mathrm{O}-\mathrm{C}$ bonding, leading to enhanced hardness and toughness of the $\mathrm{rGO} / \mathrm{Al}_{2} \mathrm{O}_{3}$ composites. Ceramic precursors are very promising raw materials that are likely to mix with graphene at the molecule level, preventing agglomeration of graphene sheets, and building hierarchical structures by in situ transformation into ceramics. However, the limited selection of precursors has restricted the type of ceramic matrix, and the complex preparation process and expensive cost of some polymer precursors hinder the broader applications of these new technologies.

\section{3 Sintering techniques of the bulk composites}

Sintering is an important process to obtain the bulk composites from the composite powder with carefully designed microstructure. Some researchers use pressureless sintering [62] and microwave sintering [63], but pressure sintering is more commonly used in the preparation of graphene/ceramic composites, because its lower sintering temperature, shorter holding time, and control of atmosphere are beneficial to graphene with low thermal stability [64]. Moreover, the pressure applied during sintering can further enhance the alignment of 2D graphene sheets and the formation of preferred orientation perpendicular to the pressure axis [65]. Generally, pressure sintering contains the multiaxial-pressed sintering by hot isostatic pressing (HIP) sintering [66] or a multi-anvil apparatus [67], and the uniaxial pressure-assisted sintering including hot-pressed (HP) sintering [68], spark plasma sintering (SPS) [69], and high-frequency induction heated sintering (HFIHS) [70,71], in which the latter is more popular due to easier operation and lower cost.

The main difference between HP, SPS, and HFIHS is the heating system: The sample is heated by the thermal conduction in a radiative furnace $[72,73]$ in HP, whereas the sample is sintered by the Joule effect caused by a pulsed direct current in SPS [72] and by an induced current in HIFHS. The different heating elements result in the shortest heating time in HIFHS and the longest time in HP. A faster sintering process is beneficial to control the grain growth, and a longer holding time is essential for the directional arrangement of graphene. Besides, for $\mathrm{GO} /$ ceramic composites, the thermal reduction of $\mathrm{GO}$ often takes place during sintering. The longer holding time and higher sintering temperature contribute to the removal of oxygen functional groups but the undesired reaction between graphene and ceramics should be avoided under high sintering temperature. Therefore, combined with relative simplicity and easy accessibility, SPS is the mostly used sintering technique in the fabrication of graphene/ ceramic composites. However, special effects such as electromigration [74] or the electromagnetic effect [72] of SPS may have unclear influences on the morphology and properties of conductive graphene sheets.

\section{4 Microstructure of the bulk composites}

To summarize, through the above-mentioned fabrication technologies, it is possible to control the microstructure 
of the graphene/ceramic composites, including the dispersion and ordered orientation of graphene sheets in the ceramic matrix as well as the bonding between graphene layers and ceramic matrix. For the graphene sources, expensive GNPs have better intrinsic properties, but it is easy to agglomerate in the composites. More homogeneous dispersion and stronger interaction between graphene and ceramics can be achieved by using GO, while EG with low cost also has great potential. Powder processing technologies are facile and widely used in the synthesis of graphene/ceramic composites. Without surface modification, it is difficult to form the good bonding between graphene and ceramics, and therefore, pores and overlapping graphene sheets may appear after sintering, as shown in Figs. 5(c) and 5(e) [50]. Usually random distribution of graphene (Fig. 6(b)) is attained in the composites, but with assistance of pressure sintering, the formation of preferred orientation becomes possible, as shown in Figs. 6(c) and 6(d) [13]. In the composites fabricated by colloidal processing, graphene sheets remain uniformly distributed in the ceramic matrix after sintering. The thin graphene sheets are usually located at the grain boundaries but sometimes lie within the grain, as shown in Figs. 5(a) and 5(b) $[16,75]$. It is difficult to build the special structure of graphene in the ceramic matrix by colloidal processing method, but through building the core-shell structure in the powder nanocomposites and viscous sintering caused by $\mathrm{SiO}_{2}$, $\mathrm{Ru}$ et al. [69] realized the anisotropic structure in $\mathrm{rGO} /$ mullite composites. Besides, new technologies with the utilization of ceramic precursors are more promising for the construction of special structures. For instance, polymethylsiloxane was infiltrated into thin reduced chemically modified graphene ( $\mathrm{rCMG})$ networks, and after cross-linking, pyrolysis, and sintering, $\mathrm{rCMG} / \mathrm{Si}-\mathrm{O}-\mathrm{C}$ composite with graphene interconnected networks (with the width of 20-30 nm) was obtained, as shown in Fig. 6(a). The different structures of graphene in the ceramic matrix realized by different synthesis technologies are illustrated in Fig. 6.

\section{Properties and applications of the graphene/ceramic bulk composites}

In this section, the recent progress and discoveries on the mechanical, electrical, electromagnetic, and thermal properties of graphene/ceramic composites are introduced. The effect of the intrinsic properties of graphene, the overall distribution of graphene in the ceramic matrix,
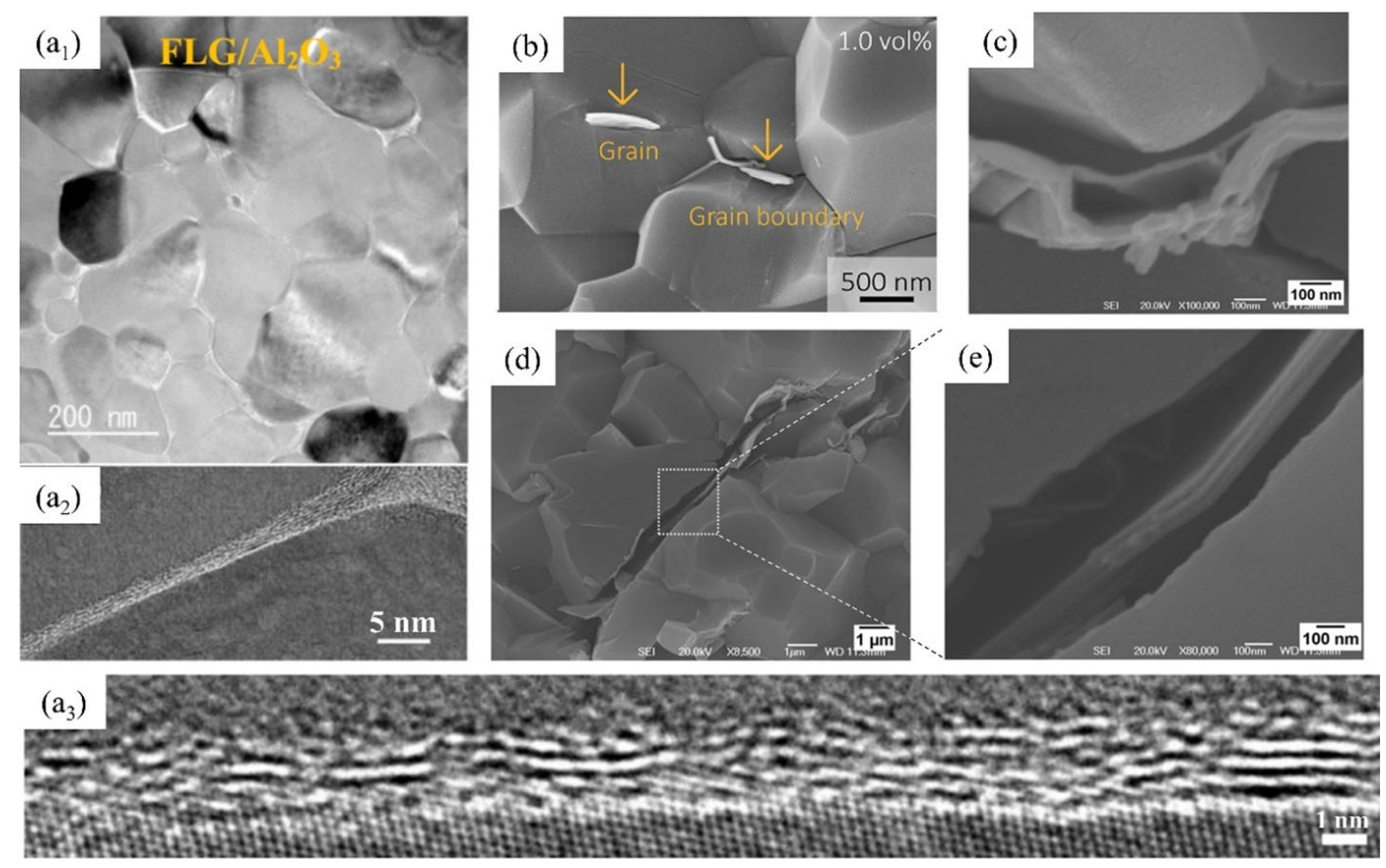

Fig. 5 Different interfacial structure and morphology of graphene in the ceramic matrix. (a) Graphene sheets lie on the grain boundary with well-contacted interface in $\mathrm{FLG} / \mathrm{Al}_{2} \mathrm{O}_{3}$ composites. Reproduced with permission from Ref. [16], (C) Elsevier Ltd. 2014. (b) Graphene sheets lie on the grain boundary or within grains in $\mathrm{GNPs} / \mathrm{Al}_{2} \mathrm{O}_{3}$ composites. Reproduced with permission from Ref. [75], (C) Elsevier B.V. 2016. (c) Agglomerations and (d, e) pores in GPL-reinforced $\mathrm{Al}_{2} \mathrm{O}_{3}$ composite. Reproduced with permission from Ref. [50], (c) Elsevier Ltd and Techna Group S.r.l. 2013. 

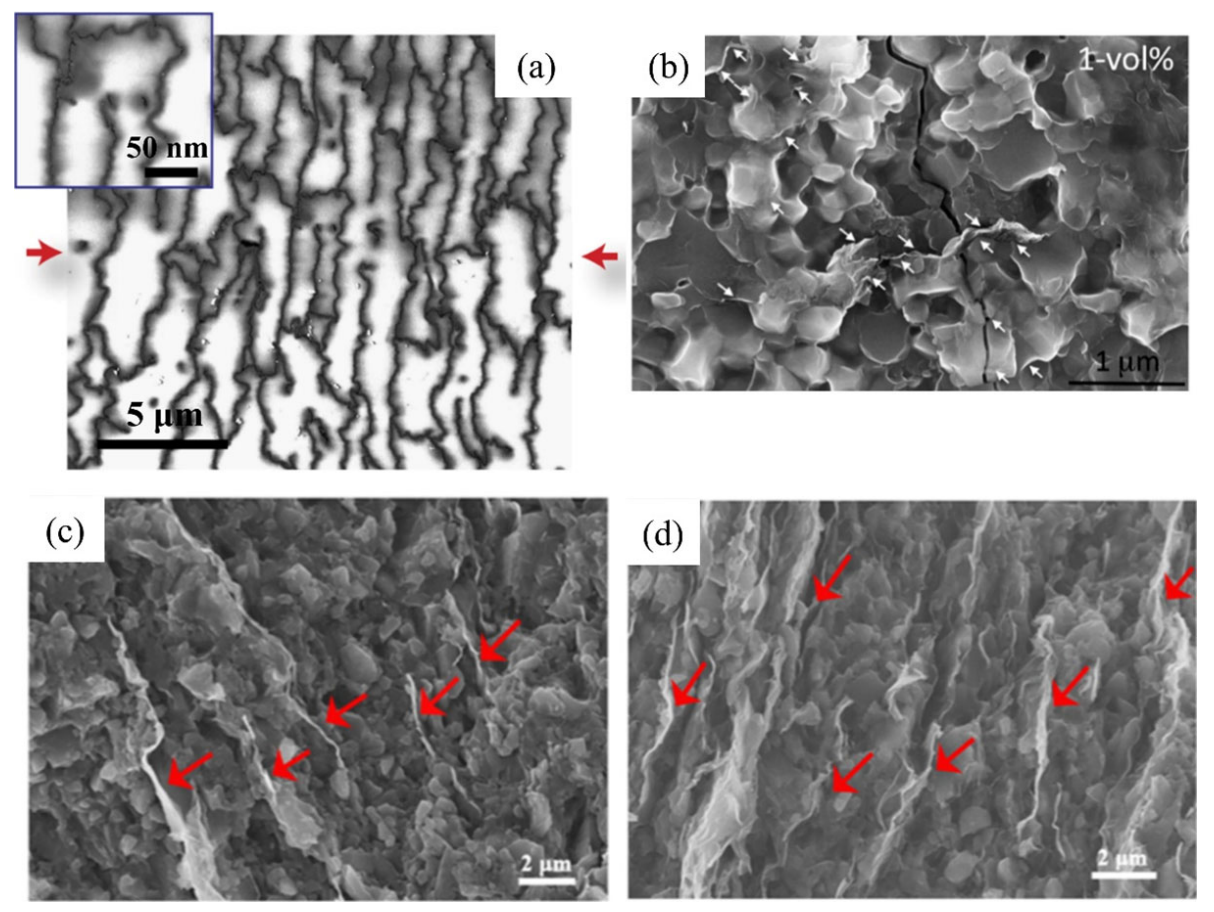

Fig. 6 Different distribution of graphene in the ceramic matrix. (a) Graphene network formed in the $\mathrm{rCMG} / \mathrm{Si}-\mathrm{O}-\mathrm{C}$ composites synthesized by the polymer-derived technology. Reproduced with permission from Ref. [14], (C) Springer Nature 2017. (b) Radom distributed graphene in the 1 vol\% GPL- $\mathrm{Si}_{3} \mathrm{~N}_{4}$ nanocomposite synthesized by the ball-milling method. Reproduced with permission from Ref. [8], (C) American Chemical Society 2011. The oriented GNPs in the (c) $3 \mathrm{wt} \%$ and (d) 5 wt $\%$ GNPs/SiC composites sintered by hot-pressed sintering. Reproduced with permission from Ref. [13], (C) Elsevier Ltd. 2018.

and the interfacial structure and bonding on the properties is discussed. The significance of smart integration of graphene in the ceramic matrix to the multifunctional applications is addressed.

\section{1 Mechanical properties and applications}

To investigate the effect of introducing graphene into the ceramic matrix, generally mechanical properties including fracture toughness, hardness, Young's modulus, flexural strength, and wear behavior are measured and studied in ceramic composites such as $\mathrm{Al}_{2} \mathrm{O}_{3}$ [17,26,27,45,50-52,70,75-85], $\mathrm{ZrO}_{2}$ [34-36,63,86-89], $\mathrm{SiC}[37,90-92], \mathrm{Si}_{3} \mathrm{~N}_{4}[8,49,93,94], \mathrm{B}_{4} \mathrm{C}[48,95,96]$, and AlN [97] composites.

Among these properties, fracture toughness has received more attention because the improvement of the brittle nature of most ceramics is still a major challenge. Testing methods of fracture toughness include micro-hardness testing $[15,73,98,99]$, the single-edge notched beam (SENB) method [52,79], the Chevron notch technique $[69,75]$, the single-edge v-notched beam (SEVNB) method [92,95], and single-edge pre-cracked beam (SEPB) method. Typically, during micro-hardness testing, fracture toughness can be simply determined by measuring the crack lengths produced by Vickers indentation; at the same time, hardness can be obtained. Therefore, microhardness testing is a popular method even though its accuracy is relatively low. In other higher-accuracy methods, notches are first introduced artificially, and specimens are then fractured by a bending test, in which preparation of a sharp notch to avoid notch passivation and approach the fracture behavior of natural cracks in ceramics becomes the key issue. Another problem is the relatively small size of specimens prepared by SPS (the mostly used sintering technique in graphene/ceramic composites), which makes it difficult to meet the requirement of testing standards. Although the reported fracture toughness values of graphene/ceramic composites were measured by different testing methods, the results definitely prove that graphene can effectively toughen the ceramic matrix. The fracture toughness of $10 \mathrm{vol} \%$ $\mathrm{GNP} / \mathrm{B}_{4} \mathrm{C}$ increased to $4.52 \mathrm{MPa} \cdot \mathrm{m}^{1 / 2}(83 \%)$ compared with $2.47 \mathrm{MPa} \cdot \mathrm{m}^{1 / 2}$ of monolithic $\mathrm{B}_{4} \mathrm{C}$ [48]. Additionally, in the $\mathrm{Al}_{2} \mathrm{O}_{3}$ matrix, the addition of only $2.5 \mathrm{vol} \% \mathrm{rGO}$ led to the high fracture toughness of $5.9 \mathrm{MPa} \cdot \mathrm{m}^{1 / 2}$, with $90 \%$ improvement [79]. The fracture mechanisms include graphene sheet pull-out, crack bridging, crack deflection, and crack branching, as illustrated in Fig. 7. 


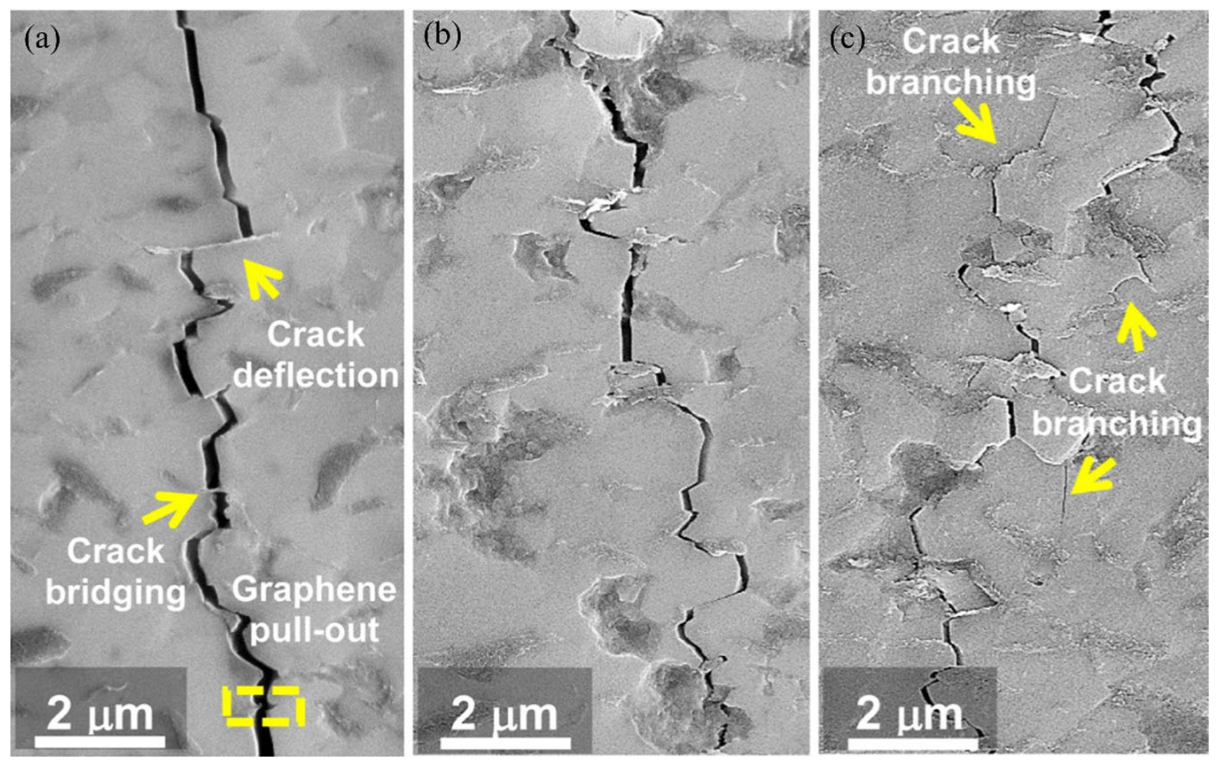

Fig. 7 Fracture mechanisms observed in the GPLs/ $\mathrm{Al}_{2} \mathrm{O}_{3}$ nanocomposites with (a) 7 vol\%, (b) 10 vol\%, and (c) 15 vol\% GPLs. Reproduced with permission from Ref. [76], (C) Elsevier Ltd. 2016.

In some cases [77,86,87], crack propagation changed from the intergranular mode to the transgranular mode, because graphene located in a grain boundary weakened the grain boundary. Tough ceramics have wide applications in ballistic armors [48], cutting tools [15], wear and corrosion resistance coatings [100], and aerospace applications [101]. For instance, compared with commercial $\mathrm{B}_{4} \mathrm{C}$ ceramic armors, the penetration depth of a bullet decreased by $40 \%$, and the protective coefficient reached 3.6 in the $1.5 \mathrm{wt} \%$ graphene $/ \mathrm{B}_{4} \mathrm{C}$ composites [18], demonstrating enormous potential in ballistic resistance applications.

Several studies reported the strengthening of the elastic modulus and flexural strength of the graphene/ ceramic composites. For example, due to the grain refinement and relatively strong bonding between graphene and the matrix, Young's modulus and flexural strength of the $1 \mathrm{wt} \% \mathrm{FLG} / \mathrm{Al}_{2} \mathrm{O}_{3}$ composite increased from $339.53 \mathrm{GPa}$ and $267.7 \mathrm{MPa}$ to $342.81 \mathrm{GPa}$ and $338.3 \mathrm{MPa}$, respectively [77]. However, in some cases [92,102], agglomerated thick graphene sheets acted as 2D defects and weakened the interfacial bonding, leading to reduced Young's modulus, which demonstrates the importance of the uniform distribution of the graphene sheets and the interfacial bonding with the matrix.

Moreover, the addition of graphene is expected to improve the wear behavior of the ceramic composites by forming tribofilms on the worn surface to provide lubrication effects. With less tangential force applied to the matrix grains, grain pull-out is impeded, leading to greatly reduced wear depth and wear rate in the 3 vol $\%$ $\mathrm{GNP} / \mathrm{SiO}_{2}$ composites [103]. Graphene sheets can also fill in the voids produced from wearing off of the matrix grains to provide an intact protecting film, resulting in an ultralow friction coefficient of $\sim 0.5$ in the $0.5 \mathrm{wt} \%$ $\mathrm{GNP} / \mathrm{Si}_{3} \mathrm{~N}_{4}$ composites [94].

Generally, the effects of graphene on the mechanical properties of the composites depend on the intrinsic mechanical properties of graphene, interfacial interaction between graphene and ceramics, and dispersion of graphene. The stress state of graphene can be measured by the Raman spectra [104]. To obtain a better strengthening and toughening effect, it is necessary to achieve a balance in interfacial interaction between graphene and the ceramic matrix. The interaction should be strong enough to achieve high density without defects such as pores and cracks, effective load transfer [50], and blocking of the generation of wear debris, but also weak enough for graphene sheet pull-out. Dispersion of graphene is another key factor. When the graphene sheets stack together and behave as graphite, the intrinsic mechanical properties of graphene will be damaged. The reduced interfacial contact area will lower the load transfer efficiency and weaken the effect of graphene sheet pull-out. To further maximize the reinforcing effect of 2D graphene sheets, preferred orientation is desired because high resistance will generate when cracks propagate perpendicularly to oriented graphene sheets [65]. However, the anisotropic structure will 
cause worse flexural strength when cracks propagate parallel to graphene sheets in some cases [48].

To further illustrate the effects of dispersion on mechanical properties, a rough comparison is conducted in Table 1. With a higher graphene content, the fracture toughness increases while the flexural strength exhibits a declining tendency, as illustrated in Fig. 8. By the mixture rule of the composites [23], it is believed that higher loading of graphene can achieve better reinforcing and toughening effects, but agglomeration will happen especially in composites synthesized by powder processing technology, which has an adverse effect on the mechanical properties. Furthermore, when the graphene sheets are relatively thin, the flexural strength of the composites $[45,79]$ has higher values and greater enhancement. When the graphene sheets are relatively thick but have preferred orientation, larger improvements
$(60 \%)$ can be observed in both flexural strength and fracture toughness [81]. These results further demonstrate the significance of achieving small thickness and preferred orientation simultaneously.

In conclusion, to further improve the mechanical behaviors of graphene/ceramic composites, it is strongly desired to establish a uniform distribution and ordered orientation for the thin graphene sheets in the ceramic matrix and a proper interfacial bonding between them.

\section{2 Electrical/electromagnetic properties and applications}

Compared with CNTs, graphene with ultrahigh electrical conductivity and a larger contact area for building the conductive path, show greater potential to dramatically alter the electrical performances of the composites. For instance, the percolation threshold of the GNSs $/ \mathrm{Al}_{2} \mathrm{O}_{3}$

Table 1 Summary of mechanical properties of graphene $/ \mathrm{Al}_{2} \mathrm{O}_{3}$ composites

\begin{tabular}{|c|c|c|c|c|c|c|c|c|c|c|}
\hline Ref. & $\begin{array}{l}\text { Carbon } \\
\text { sources }\end{array}$ & $\begin{array}{l}\text { Synthesis } \\
\text { method }\end{array}$ & Content & $\begin{array}{l}\text { Thickness } \\
\text { of graphene } \\
\text { sheets (nm) }\end{array}$ & $\begin{array}{l}\text { Orien- } \\
\text { tation }\end{array}$ & $\begin{array}{c}\text { Flexural } \\
\text { strength } \\
\text { (improvement) } \\
(\mathrm{MPa})\end{array}$ & $\begin{array}{c}\text { Fracture } \\
\text { toughness } \\
(\mathrm{improvement}) \\
\left(\mathrm{MPa} \cdot \mathrm{m}^{1 / 2}\right)\end{array}$ & $\begin{array}{l}\text { Testing } \\
\text { method }\end{array}$ & $\begin{array}{c}\text { Modulus } \\
\text { (improvement) } \\
(\mathrm{GPa})\end{array}$ & $\begin{array}{c}\text { Hardness } \\
\text { (improvement) } \\
(\mathrm{GPa})\end{array}$ \\
\hline$[50]$ & $\mathrm{rGO}$ & $\begin{array}{l}\text { Powder } \\
\text { processing }\end{array}$ & $0.38 \mathrm{vol} \%$ & $8-110$ & $x$ & $523(31 \%)$ & $4.49(27 \%)$ & SEVNB & - & $17.66(-2 \%)$ \\
\hline [80] & rGO & $\begin{array}{l}\text { Powder } \\
\text { processing }\end{array}$ & 0.75 vol $\%$ & $8-110$ & $x$ & $550(60 \%)$ & $4.5(60 \%)$ & SEVNB & - & $18.58(-3 \%)$ \\
\hline [27] & GNP & $\begin{array}{c}\text { Powder } \\
\text { processing }\end{array}$ & $0.8 \mathrm{vol} \%$ & - & $\sqrt{ }$ & - & $3.7(28 \%)$ & $\begin{array}{c}\text { Chevron } \\
\text { notch }\end{array}$ & $373(-2 \%)$ & $21.6(-6 \%)$ \\
\hline [26] & GNP & $\begin{array}{c}\text { Powder } \\
\text { processing }\end{array}$ & 0.8 vol $\%$ & - & - & - & $4.3(34 \%)$ & $\begin{array}{c}\text { Chevron } \\
\text { notch }\end{array}$ & $292(-12 \%)$ & $21.9(-2 \%)$ \\
\hline$[45]$ & EG & $\begin{array}{l}\text { Powder } \\
\text { processing }\end{array}$ & $0.3 \mathrm{vol} \%$ & $3-25$ & $x$ & $708(100 \%)$ & $3.89(25 \%)$ & Indentation & - & $23.7(26 \%)$ \\
\hline [82] & GNP & $\begin{array}{c}\text { Powder } \\
\text { processing }\end{array}$ & $0.36 \mathrm{vol} \%$ & $<220$ & $x$ & - & $5.8(35 \%)$ & Indentation & $370(-16 \%)$ & - \\
\hline [81] & GNP & $\begin{array}{l}\text { Powder } \\
\text { processing }\end{array}$ & 0.75 vol $\%$ & $<100$ & $\sqrt{ }$ & $461(60 \%)$ & $6.2(60 \%)$ & Indentation & - & - \\
\hline [77] & FLG & $\begin{array}{l}\text { Powder } \\
\text { processing }\end{array}$ & 1 vol $\%$ & - & $x$ & $338(26 \%)$ & $4.1(68 \%)$ & Indentation & $343(0)$ & $18.91(-6 \%)$ \\
\hline [76] & GNP & $\begin{array}{l}\text { Powder } \\
\text { processing }\end{array}$ & 3 vol $\%$ & $<50$ & $\sqrt{ }$ & - & $3.8(27 \%)$ & Indentation & - & - \\
\hline [70] & GNP & $\begin{array}{c}\text { Powder } \\
\text { processing }\end{array}$ & $\begin{array}{c}3 \mathrm{wt} \% \\
(\sim 5 \mathrm{vol} \%)\end{array}$ & - & $x$ & - & $5(22 \%)$ & Indentation & - & $20.1(7 \%)$ \\
\hline [51] & $\mathrm{GO}$ & $\begin{array}{l}\text { Colloidal } \\
\text { processing }\end{array}$ & $0.6 \mathrm{vol} \%$ & $1-3$ & $x$ & - & - & - & $470(-6 \%)$ & $25.8(0)$ \\
\hline$[52]$ & $\mathrm{GO}$ & $\begin{array}{l}\text { Colloidal } \\
\text { processing }\end{array}$ & $2.18 \mathrm{vol} \%$ & 3 & $\times$ & $417(3 \%)$ & $5.3(23 \%)$ & SENB & $298(-26 \%)$ & - \\
\hline [79] & $\mathrm{GO}$ & $\begin{array}{l}\text { Colloidal } \\
\text { processing }\end{array}$ & $2.5 \mathrm{vol} \%$ & 10 & $x$ & $637(105 \%)$ & $5.87(90 \%)$ & SENB & $350(-12.5 \%)$ & $17.6(0)$ \\
\hline [17] & $\mathrm{GO}$ & $\begin{array}{l}\text { Molecular } \\
\text { level mixing }\end{array}$ & $3 \mathrm{vol} \%$ & $<100$ & $x$ & $425(21 \%)$ & $9.2(120 \%)$ & Indentation & - & - \\
\hline [75] & GNP & $\begin{array}{l}\text { Molecular } \\
\text { level mixing }\end{array}$ & 1 vol $\%$ & - & $x$ & - & $3.8(5 \%)$ & SENB & - & $19.1(-7 \%)$ \\
\hline$[84,85]$ & GO & $\begin{array}{c}\text { Molecular } \\
\text { level mixing }\end{array}$ & 4 vol $\%$ & - & $\sqrt{ }$ & - & $5.6(13 \%)$ & SENB & - & - \\
\hline
\end{tabular}



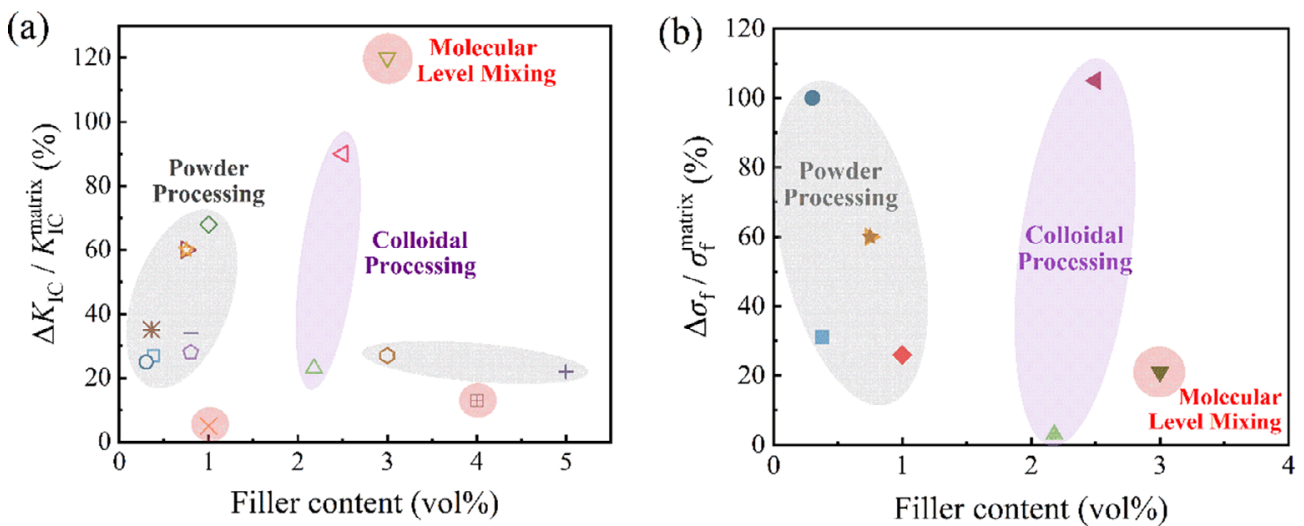

Fig. 8 Comparison of improvement of (a) fracture toughness and (b) flexural strength in the reported researches about graphene $/ \mathrm{Al}_{2} \mathrm{O}_{3}$ composites synthesized by powder processing [26,27,45,50,70,76,77,80-82], colloidal processing [52,79], and molecular level mixing [17,75,84,85] technologies. Reproduced with permission from Ref. [26], (C) Elsevier Ltd and Techna Group S.r.1. 2016; Ref. [27], (C) Elsevier Ltd. 2013; Ref. [45], (C) WILEY-VCH Verlag GmbH \& Co. KGaA, Weinheim 2014; Ref. [50], (C) Elsevier Ltd and Techna Group S.r.l. 2013; Ref. [70], (C) Elsevier Ltd. 2014; Ref. [76], (C Elsevier Ltd. 2016; Ref. [77], (C) Elsevier Ltd. 2017; Ref. [80], (C) American Chemical Society 2016; Ref. [81], C Elsevier Ltd and Techna Group S.r.1. 2016; Ref. [82], (C) Elsevier Ltd. 2016; Ref. [52], (C) Elsevier Ltd. 2015; Ref. [79], (C) Elsevier Ltd. 2018; Ref. [17], C Elsevier Ltd. 2014; Ref. [75], (C) Elsevier B.V. 2016; Ref. [84], (C) China National Intellectual Property Administration 2019; Ref. [85], (C) Harbin Institute of Technology 2019.

composite was as low as 3 vol\%. When the GNSs content increased to $15 \mathrm{vol} \%$, the electrical conductivity achieved $5709 \mathrm{~S} / \mathrm{m}$, which was $170 \%$ higher than the highest conductivity previously reported in $\mathrm{CNT} / \mathrm{Al}_{2} \mathrm{O}_{3}$ composites [105]. However, the improvement of the electrical conductivity greatly depends on the dispersion of graphene in the ceramic matrix. With the same $\mathrm{Al}_{2} \mathrm{O}_{3}$ matrix, Çelik et al. [76] attained an electrical conductivity of $0.34 \mathrm{~S} / \mathrm{m}$ with 7 vol\% GPLs, while Qing et al. [47] achieved a similar value of $\sim 0.4 \mathrm{~S} / \mathrm{m}$ at a much lower graphene content of $0.5 \mathrm{vol} \%$ with a better distribution of graphene. Interestingly, the charge carrier type of the composites changed from p-type to n-type with increasing graphene content because of hole-doping effect induced by the ceramic matrix [9]. The control of oxygen vacancy concentration of the ceramic matrix such as yttria-stabilized zirconia (YSZ) can further modulate the hole-doping level, which has significant meaning in the novel application of semiconductors [16]. Besides, composites with anisotropic structure have a great impact on the electrical conductivity in different directions [106]. For the $0.47 \mathrm{vol} \% \mathrm{rGO} /$ mullite composites with a preferred orientation, the cross-plane electrical conductivity was only $0.55 \mathrm{~S} / \mathrm{m}$, while the in-plane conductivity increased to $190 \mathrm{~S} / \mathrm{m}$ [69]. Since studies on the electrical conductivity and percolation threshold of graphene/ceramic composites have been fully investigated [1-3,64,107], here we would like to focus on the burgeoning applications in electromagnetic (EM) interference shielding. When magnetic materials are not incorporated in the composites, electrical conductivity plays the dominant role in EM properties.

With the development of electronic devices for communication technologies or military defense purposes, electromagnetic interference (EMI), and EM pollution have become a serious problem and it is essential to block the EM wave. The total EMI shielding effectiveness or efficiency $\left(S E_{\mathrm{T}}\right)$ should be larger than $20 \mathrm{~dB}$ to block more than $99 \%$ of an incident EM wave [108]. Generally, $S E_{\mathrm{T}}$ comprises $S E_{\mathrm{R}}$ (reflection), $S E_{\mathrm{A}}$ (absorption), and $S E_{\mathrm{M}}$ (internal multiple reflection) [109]. High $S E_{\mathrm{R}}$ requires a high concentration of mobile charge carriers, and strong dielectric loss or magnetic loss caused by dipoles contributes to high $S E_{\mathrm{A}}$. Special structures with a large specific area or interface areas such as porous foam structure [110-112], composite structure, or other hierarchical structure [58] can also enhance $S E$. However, for microwave heating devices or antiradar applications, EM-absorbing materials are desired, which are expected to have a broad effective absorption bandwidth $(\mathrm{EAB})$ and a minimum reflection coefficient or loss $\left(R C_{\min }\right.$ of $\left.R L_{\min }\right)$ (lower than $-10 \mathrm{~dB}$ for the absorption of more than $90 \%$ EM energy [113]). In these cases, good impedance matching is required to minimize reflection, and absorption becomes dominant in energy dissipation.

Traditional metal materials with high electrical 
conductivity can reflect most of the incident EM wave, but the high density, weak corrosion resistance, and bad impedance matching hinder their applications in microwave absorption (MA) [114]. Therefore, ceramics become promising materials for their structural stability, oxidation resistance, and excellent mechanical properties at high temperatures. Even though most ceramics are EM transparent, the introduction of conductive fillers such as graphene can easily solve this problem and adjust EM properties of the ceramic matrix; conversely, a low dielectric constant of ceramic can improve impedance matching of highly conductive graphene $[60,115]$.

Recent studies of the graphene/ceramic composites [13,47,57-62,68,69,116-122] focus on EM properties
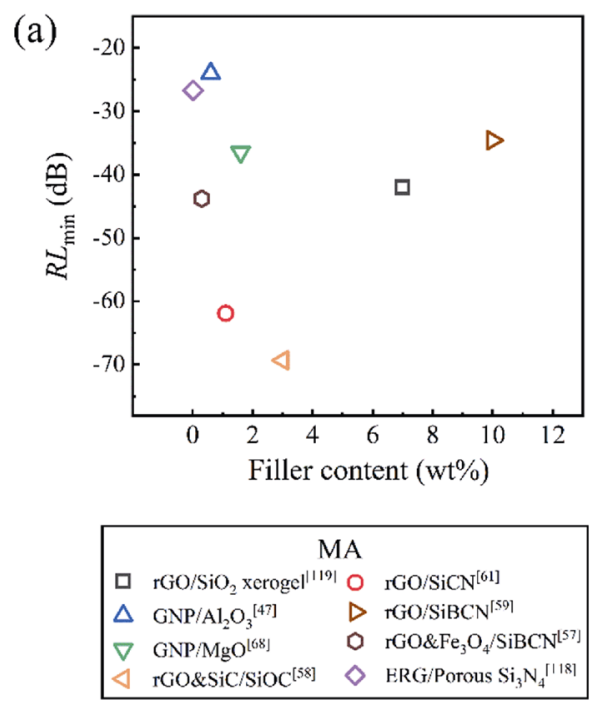

in the $\mathrm{X}$-band $(8.2-12.4 \mathrm{GHz})$ for military and communication applications [62], the $\mathrm{Ku}$-band (12.4-18 GHz) for small aperture terminal systems [109], or the K-band (18-26.5 GHz) for intelligent transportation systems and vehicle radar [69]. The excellent EM properties of the composites are achieved, as shown in Fig. 9. For example, the 2.5 vol\% GNPs/ $\mathrm{MgO}$ composite with a thickness of $1.5 \mathrm{~mm}$ exhibited an $R C_{\text {min }}$ of $-36.5 \mathrm{~dB}$ with $\mathrm{EAB}$ of $2 \mathrm{GHz}$ [68]. The $R C_{\text {min }}$ of the $\mathrm{rGO}-\mathrm{SiCN}$ composite reached $-61.9 \mathrm{~dB}$ with $\mathrm{EAB}$ of $\sim 3 \mathrm{GHz}$ in a 2-mm-thick sample with $2.5 \mathrm{wt} \% \mathrm{GO}$ content. When the GO content increased to $12 \mathrm{wt} \%$, the EMI $S E$ of the $\mathrm{rGO}-\mathrm{SiCN}$ composite had a high value of $41.2 \mathrm{~dB}$ [61]. The 2 vol\% $\mathrm{GN} / \mathrm{Al}_{2} \mathrm{O}_{3}$ composite presented an EMI $S E$ higher than

(b)

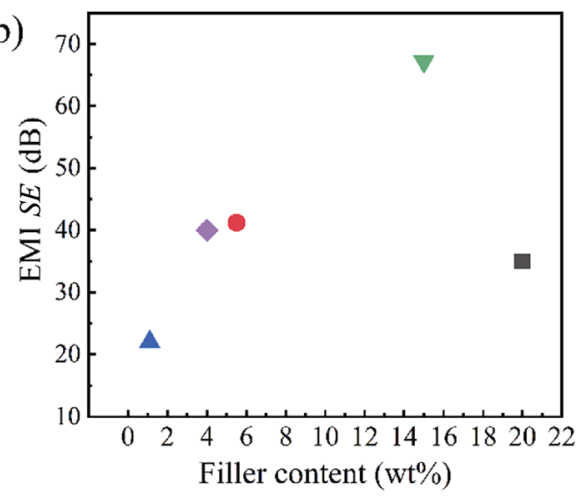

\begin{tabular}{|c|}
\hline EMI shielding \\
$\mathrm{rGO} / \mathrm{SiO}_{2}$ xerogel $^{[116]}$ \\
$\mathrm{GNP} / \mathrm{BaTiO}_{3}{ }^{[62]}$ \\
$\mathrm{GNP} / \mathrm{Al}_{2} \mathrm{O}_{3}{ }^{[47]}$ \\
$\mathrm{rGO} / \mathrm{SiCN}^{[61]}$ \\
$\nabla \mathrm{rGO} \& \mathrm{CNT} / \mathrm{SiCN}^{[60]}$ \\
\hline
\end{tabular}

Fig. 9 Comparison of (a) $R L_{\min }$ and (b) EMI $S E$ in the X-band at room temperature of the reported graphene/ceramic composites [47,57-62,68,116,118,119]. Reproduced with permission from Ref. [47], (C) The Royal Society of Chemistry 2016; Ref. [57], (C) American Chemical Society 2018; Ref. [58], (C) Elsevier Ltd. 2016; Ref. [59], (C) Elsevier Ltd and Techna Group S.r.l. 2018; Ref. [60], (C) Acta Materialia Inc. Published by Elsevier Ltd. 2017; Ref. [61], (C) The Royal Society of Chemistry 2017; Ref. [62], (C) The Royal Society of Chemistry 2016; Ref. [68], (C) Elsevier Ltd. 2017; Ref. [116], (C) WILEY-VCH Verlag GmbH \& Co. KGaA, Weinheim 2014; Ref. [118], (C) WILEY-VCH Verlag GmbH \& Co. KGaA, Weinheim 2018; Ref. [119], (C) The Royal Society of Chemistry 2015.
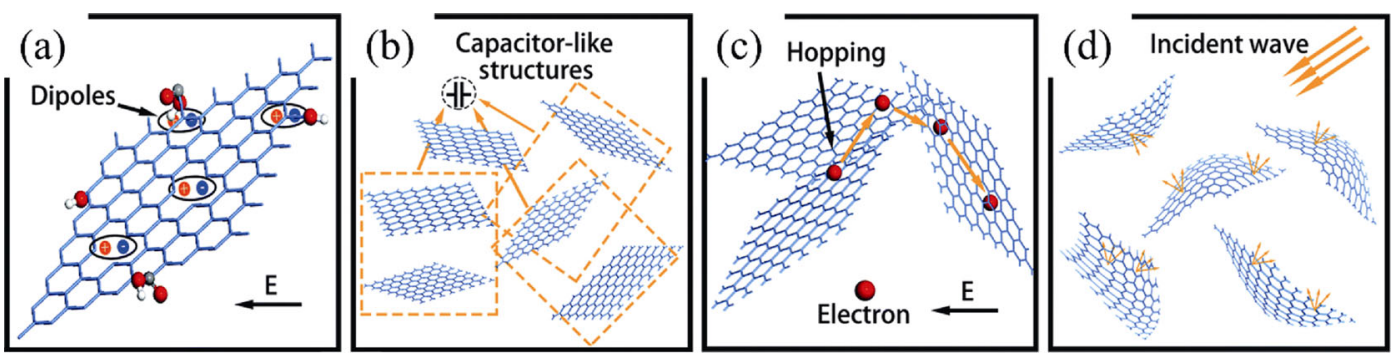

Fig. 10 Schematic illustrations for microwave absorption properties of the graphene composites: (a) polarization and relaxation, (b) formation of capacitor-like structures, (c) electronic transport and network, and (d) microwave propagation model and wave scattering. Reproduced with permission from Ref. [119], (c) Royal Society of Chemistry 2015. 
$36 \mathrm{~dB}$ over the whole X-band even at $400{ }^{\circ} \mathrm{C}$ [47]. The improved EM properties are attributed to the polarization relaxation by functional groups and defects of rGO $[69,116]$, conduction loss from conduction network formed by graphene, multiple reflections at interfaces and dielectric loss of micro-capacitors, which is formed by a pair of graphene and ceramics including interfacial polarization due to accumulated space charges, as illustrated in Fig. 10 [119].

To further enhance these effects, it is still required to achieve a better dispersion of graphene and interfacial interaction between graphene and ceramics. As illustrated in Fig. 9, Si-C-based ceramics [57-61] have attracted much attention because of its excellent thermal stabilities. These ceramic matrixes can be easily introduced by a polymer-derived technology, which is beneficial for better dispersion of graphene and construction of the special structures. Homogeneous dispersion of thinner graphene sheets can lower the percolation threshold by forming a conductive path at lower concentration $[68,123]$ and increase the contact area with the ceramics for larger interfacial polarization. Moreover, the formation of preferred orientation or 3D network of graphene sheets is propitious to the construction of a microcapacitor network and the enhancement of multiple reflections [13,69]. Besides, compared with the rGO-SiCN composite fabricated by physical blending, a composite obtained from a single-source precursor synthesized by the amidation reaction between GO and polysilazane has stronger interfacial bonding, leading to superior EM performance [61], indicating the significance of interfacial interaction.

Current studies indicate that graphene/ceramic composites have outstanding EM performance, but high-temperature EM properties still need deeper exploration because of the relatively low thermal stability of graphene. For example, EM properties of the $\mathrm{C} / \mathrm{SiC}$ composite under $600{ }^{\circ} \mathrm{C}[121]$ and the $\mathrm{rGO} @ \mathrm{Fe}_{3} \mathrm{O}_{4} / \mathrm{SiBCN}$ composite after oxidation at $600{ }^{\circ} \mathrm{C}$ for $2 \mathrm{~h}$ [57] were explored. Ceramic matrix prevented thermal damage to graphene to a certain extent, and these composites still exhibited excellent EM properties. However, the EM properties of composites under long-term heat treatment need further exploration. Besides, further improvement of EM properties by incorporating a second filler or forming a hierarchical structure also deserves exploration; for instance, after the addition of $15 \mathrm{wt} \% \mathrm{GO} / \mathrm{CNTs}$, the $\mathrm{SiCN}$ composite exhibited an extraordinarily high $\mathrm{SE}$ value of $67.2 \mathrm{~dB}$ [60]. Han et al. [58] reported a hierarchical structure of 1D $\mathrm{SiC}$ nanowires and 2D graphene sheets in the SiOC composite, leading to outstanding EM wave absorption ability with an $R C_{\min }$ value of $-69.3 \mathrm{~dB}$.

In summary, rising attention has fallen on the EM properties of graphene/ceramic composites. For practical applications, the achievement of exceedingly good EM performance (wider effective bandwidth, lower RC value or larger SE value, and high-temperature stability) of composites with lower filler content and smaller thickness is the main target. The realization of better dispersion and enhancement of interfacial interaction may be the key factors in achieving this goal.

\section{3 Thermal properties and applications}

As stated in Section 3.2, thermal stability is one of the concerns in the graphene/ceramic composites. When the temperature was above $600{ }^{\circ} \mathrm{C}$, oxidation with substantial weight loss of $\sim 77 \mathrm{wt} \%$ occurred for monolithic graphene sheets under air atmosphere, whereas only $0.2 \mathrm{wt} \%$ weight loss was observed in the $0.5 \mathrm{wt} \%$ graphene $/ \mathrm{Al}_{2} \mathrm{O}_{3}$ composites under the same condition [124], proving that integration of graphene with the ceramic matrix can effectively protect graphene sheets from heat damage.

Conversely, graphene is expected to adjust the thermal conductivity of ceramic composites. By incorporating $2 \mathrm{wt} \%$ graphene with high thermal and electrical conductivity into the $\mathrm{SiC}$ matrix, average velocity, mean free path of the phonons, and the number of free-moving electric-charge carriers increased, leading to improved thermal conductivity from 114 to 145 $\mathrm{W} /(\mathrm{m} \cdot \mathrm{K})$ in the composites [125]. However, in some cases [126-128], with higher graphene content and a stronger grain refinement effect, more interfaces introduced by graphene as well as the defects and pores caused by graphene agglomeration will enhance the phonon scattering, resulting in decreased thermal conductivity. For instance, compared with pure AlN ceramic, the thermal conductivity of the $9.5 \mathrm{wt} \%$ GPLs/AlN composite decreased from 58.2 to 19.8 $\mathrm{W} /(\mathrm{m} \cdot \mathrm{K})[129]$. Similar to the electrical conductivity, anisotropic thermal conductivity can be observed in the composites with preferred orientation. In the highly oriented GNPs/SiC composites, the in-plane thermal conductivity was improved while the cross-plane conductivity was reduced with increasing graphene content. When the graphene contents increased to $20 \mathrm{vol} \%$, the in-plane conductivity was 3.4 times higher than the cross-plane conductivity, owing to the much 
lower intrinsic conductivity of the aligned GNPs in the $c$-axis [130]. Similar changing tendency also occurred in the GNPs/SiAlON composite [131], and the thermal conductivity differences between different directions were enlarged as the GNPs content increased. Therefore, depending on different application requirements, it is necessary to design and control the key factors of microstructure, including the homogeneous dispersion of graphene without agglomeration, interfacial thermal resistance and special structures such as preferred orientation and 3D grapheme-foam-based [132] or porous structure [133]. For applications in thermal management, Zhou et al. [134] coated the graphene films on a porous $\mathrm{Al}_{2} \mathrm{O}_{3}$ foam, and the as-prepared composite exhibited an ultralow sheet electrical resistance of $0.11 \Omega \cdot \mathrm{sq}^{-1}$ and enhanced thermal conductivity of $8.28 \mathrm{~W} /(\mathrm{m} \cdot \mathrm{K})$, in which the graphene framework offers numerous conductive pathways for electronic and thermal transport, as illustrated in Fig. 11. Further incorporation of stearic acid (a phase-change material) into the foam still reserved a high thermal conductivity of $2.39 \mathrm{~W} /(\mathrm{m} \cdot \mathrm{K})$ and latent heat of $38 \mathrm{~J} / \mathrm{g}$, indicating great potential in applications of heat transfer and thermal energy storage [19].

\section{4 Other applications of the graphene/ceramic bulk composites}

Incorporating graphene into ceramics has significantly altered the mechanical, electrical, and thermal properties of the composites. Inspired by the combination and derivation of these performances, novel applications can be possible, such as self-monitor damage sensing, energy conversion, etc.

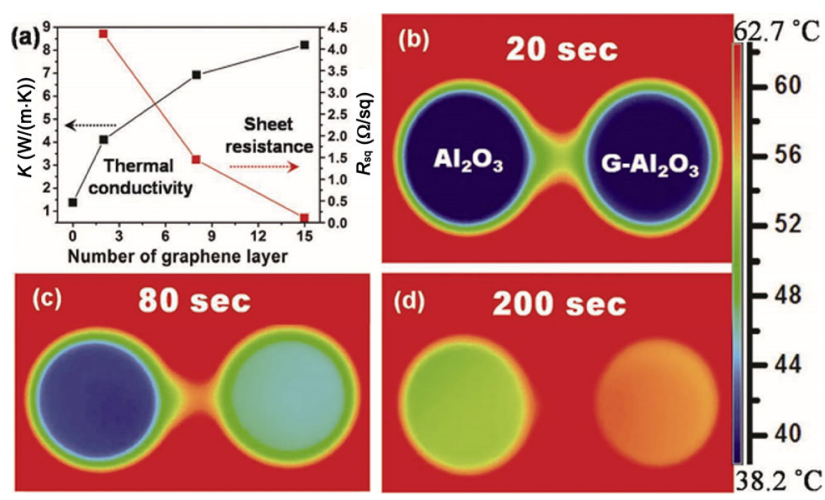

Fig. 11 (a) Thermal conductivity and sheet resistance of the graphene $(\mathrm{G}) / \mathrm{Al}_{2} \mathrm{O}_{3}$ ceramic samples. (b-d) Thermal transport evolution of the $\mathrm{Al}_{2} \mathrm{O}_{3}$ and $\mathrm{G} / \mathrm{Al}_{2} \mathrm{O}_{3}$ ceramic samples. Reproduced with permission from Ref. [134], (C) WILEY-VCH Verlag GmbH \& Co. KGaA, Weinheim 2013.

\subsubsection{Self-monitor damage sensing}

As stated in Section 3.2, incorporating graphene is expected to significantly enhance the electrical conductivity of the composites, which enables the applications of the Joule heating effect, as illustrated in Fig. 12(a). Besides, well construction of the unique structure in the composites can achieve a high electrical conductivity and high fracture toughness at the same time, which makes it possible to detect the damage of the structural integrity of the composites. In the $\mathrm{Si}-\mathrm{O}-\mathrm{C}$ composites [14], graphene network was carefully introduced to form the highly conductive network and provide huge fracture resistance. With stable crack propagation, the load can be released before fracture and the recovered network lead to recovered voltage. Therefore, the graphene network can be utilized to sense voltage change caused by the crack propagation in the composites. Besides, the fine interconnected structure leads to high sensitivity (a crack length with only $10 \mu \mathrm{m}$ can cause a voltage change as large as $0.1 \mathrm{mV}$ ), indicating the excellent structural integrity sensing ability of the composite (Fig. 12(b)).

\subsubsection{Energy conversion device}

As described in Sections 3.2 and 3.3, the addition of graphene can cause great changes in both electrical conductivity and thermal conductivity of the composites, but the variations may be quite different in the same composites. For example, Kocjan et al. [135] discovered electric and thermal decoupling in the YSZ composites with the graphene-like network. Due to a highly electrically conductive network, the electrical conductivity of the composites was improved by 14 orders of magnitude, whereas the thermal conductivity only increased by $6 \%$ because of the strong interfacial thermal resistance, which shows the potential of thermoelectricity improvement. Srivastava et al. [12] further explored the thermoelectric properties of the graphene/ceramic composites. By building the anisotropic structure, the $1 \mathrm{wt} \%$ graphene $/ \mathrm{Sr}_{0.8} \mathrm{La}_{0.067} \mathrm{Ti}_{0.8} \mathrm{Nb}_{0.2} \mathrm{O}_{3-\delta}$ composite had a high in-plane electrical conductivity and a low cross-plane thermal conductivity, leading to a high thermoelectric figure of merit of $\sim 0.25$ at $1000 \mathrm{~K}$. The improvement as high as $80 \%$ in the thermoelectric figure of merit was also attained in the $\sim 0.3 \mathrm{wt} \%$ rGO/Nb-doped $\mathrm{SrTiO}_{3}$ composite [136], exhibiting a great potential for applications in efficient conversion of heat to electricity. 
(a)
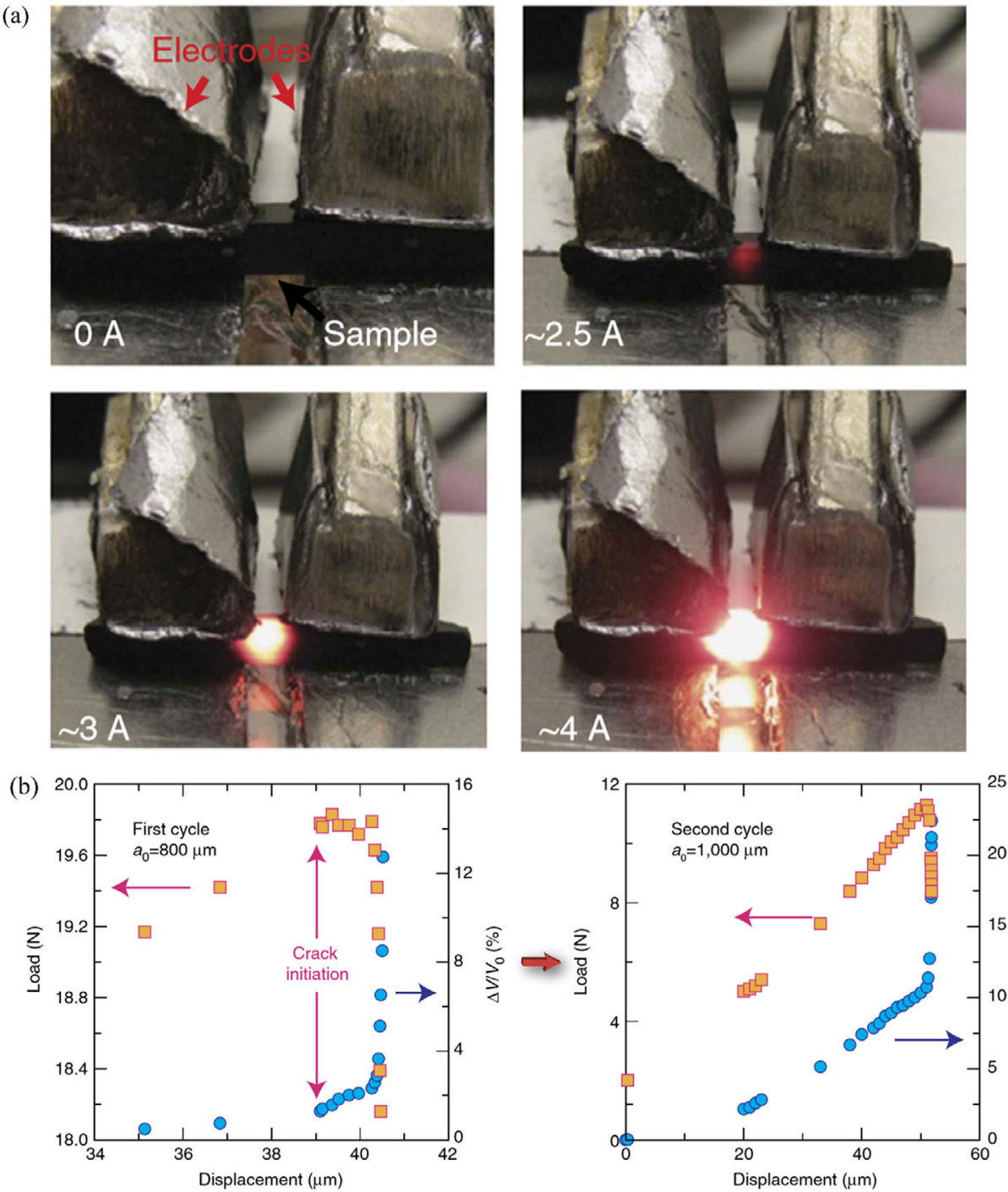

Fig. 12 (a) Joule heating effect of the composite. (b) Load displacement curves during the bending of a notched sample and simultaneous variation of the voltage. Reproduced with permission from Ref. [14], (c) Springer Nature 2017.

\section{Conclusions and outlook}

Here, we give a brief introduction of the graphene/ ceramic composites. In the recent 10 years, the graphene/ceramic composites have stimulated worldwide interests because graphene with outstanding overall properties has a great potential to broaden applications of ceramic materials, including not only enhanced mechanical behaviors, electrical performances, and thermal properties but also novel applications in MA, EMI shielding, damage sensors, energy conversion devices, and so on.

To further maximize the function of graphene in the ceramic matrix, suitable dispersion of graphene sheets, control of the interface, and special structures are critical factors. Retention and full utilization of the multifunctional characteristics of graphene are also worth deeper investigation. Therefore, we list part of critical factors and perspectives as follows:

1) Graphene sources with different characteristics, intrinsic performances, and fabrication costs: We should notice that, during the synthesis process, defects in the graphene lattice may arise and damage the structural integrity and intrinsic properties of graphene sheets, which is of high significance to the final performance of the composites. Graphene with a near-perfect nature is an ideal raw material, but the agglomeration problem arises during mixing, whereas GO with defects and functional groups offers the solution for avoiding agglomeration, but reduction degree is notable for different applications. EG is a promising economical material that deserves more trials. 
2) Synthesis technologies of composites: Facile powder and traditional colloidal processing technologies were widely used in previous studies. However, to design and construct a special fine structure such as building a thin graphene network for multifunctional applications, it is more promising to adopt modified colloidal methods and newly developed polymer-derived technologies with the utilization of ceramic precursors.

3) Mechanical behaviors: Good dispersion and hierarchical structure of graphene sheets in the ceramic matrix and proper interfacial bonding are meaningful according to the strengthening and toughening mechanisms such as graphene sheet pull-out, crack bridging, crack deflection, and crack branching.

4) EM performance: How to maintain thin graphene sheets to increase interfaces and form a conductive network is also important in the enhancement of the EM wave absorption ability. Further improvement may be realized by a second filler or a hierarchical structure. The high-temperate properties of the composites also need further exploration.

5) Thermal properties: To adjust the thermal performance of the composites, essential factors including thermal properties of graphene changed by defects, design of hierarchical structure such as graphene orientation or network, and control of interfacial thermal resistance should be carefully considered.

6) The search for multifunctional applications of the composites. It is very promising to study how one can design a unique fine structure to make use of the versatility of graphene and combine various performance characteristics to explore wider applications. For instance, with a highly electrically conductive network and abundantly exposed graphene edges, the graphene/ ceramic composites of high structural stability indicate great potential in applications of catalysis and the field emission effect.

7) For practical applications, improvement of processing strategies to achieve better performance at lower graphene contents and to meet requirements such as light-weight, flexibility, or large-scale production is also necessary.

\section{Acknowledgements}

This work was supported by the National Key R\&D Program of China (No. 2017YFA0700705) and the National Natural Science Foundation of China (No. 51590893).

\section{References}

[1] Fan YC, Wang LJ, Jiang W. Graphene based oxide ceramic composites with high mechanical and functional performance: From preparation to property. J Inorg Mater 2018, 33: 138.

[2] Nieto A, Bisht A, Lahiri D, et al. Graphene reinforced metal and ceramic matrix composites: A review. Int Mater Rev 2017, 62: 241-302.

[3] Porwal H, Grasso S, Reece MJ. Review of grapheneceramic matrix composites. Adv Appl Ceram 2013, 112: 443-454.

[4] Lee C, Wei X, Kysar JW, et al. Measurement of the elastic properties and intrinsic strength of monolayer graphene. Science 2008, 321: 385-388.

[5] Miao XC, Tongay S, Petterson MK, et al. High efficiency graphene solar cells by chemical doping. Nano Lett 2012, 12: 2745-2750.

[6] Raccichini R, Varzi A, Passerini S, et al. The role of graphene for electrochemical energy storage. Nat Mater 2015, 14: 271-279.

[7] Balandin AA, Ghosh S, Bao WZ, et al. Superior thermal conductivity of single-layer graphene. Nano Lett 2008, 8: 902-907.

[8] Walker LS, Marotto VR, Rafiee MA, et al. Toughening in graphene ceramic composites. ACS Nano 2011, 5: 3182 3190.

[9] Fan YC, Jiang W, Kawasaki A. Highly conductive few-layer graphene $/ \mathrm{Al}_{2} \mathrm{O}_{3}$ nanocomposites with tunable charge carrier type. Adv Funct Mater 2012, 22: 3882-3889.

[10] Zhan GD, Kuntz JD, Garay JE, et al. Electrical properties of nanoceramics reinforced with ropes of single-walled carbon nanotubes. Appl Phys Lett 2003, 83: 1228-1230.

[11] Zhu YW, Murali S, Cai WW, et al. Graphene and graphene oxide: Synthesis, properties, and applications. Adv Mater 2010, 22: 3906-3924.

[12] Srivastava D, Norman C, Azough F, et al. Anisotropy and enhancement of thermoelectric performance of $\mathrm{Sr}_{0.8} \mathrm{La}_{0.067} \mathrm{Ti}_{0.8} \mathrm{Nb}_{0.2} \mathrm{O}_{3-\delta}$ ceramics by graphene additions. J Mater Chem A 2019, 7: 24602-24613.

[13] Chen, Tan YQ, Han XC, et al. Enhanced electromagnetic interference shielding properties of silicon carbide composites with aligned graphene nanoplatelets. $J$ Eur Ceram Soc 2018, 38: 5615-5619.

[14] Picot OT, Rocha VG, Ferraro C, et al. Using graphene networks to build bioinspired self-monitoring ceramics. Nat Commun 2017, 8: 14425.

[15] Li ZL, Zhao J, Sun JL, et al. Reinforcement of $\mathrm{Al}_{2} \mathrm{O}_{3} / \mathrm{TiC}$ ceramic tool material by multi-layer graphene. Ceram Int 2017, 43: 11421-11427.

[16] Fan YC, Kang LJ, Zhou WW, et al. Control of doping by matrix in few-layer graphene/metal oxide composites with highly enhanced electrical conductivity. Carbon 2015, 81: 83-90. 
[17] Lee B, Koo MY, Jin SH, et al. Simultaneous strengthening and toughening of reduced graphene oxide/alumina composites fabricated by molecular-level mixing process. Carbon 2014, 78: 212-219.

[18] Yin ZB, Yuan JT, Chen MD, et al. Mechanical property and ballistic resistance of graphene platelets $/ \mathrm{B}_{4} \mathrm{C}$ ceramic armor prepared by spark plasma sintering. Ceram Int 2019 , 45: 23781-23787.

[19] Zhou M, Bi H, Lin TQ, et al. Heat transport enhancement of thermal energy storage material using graphene/ceramic composites. Carbon 2014, 75: 314-321.

[20] Zhang YH, Heo YJ, Park M, et al. Recent advances in organic thermoelectric materials: Principle mechanisms and emerging carbon-based green energy materials. Polymers 2019, 11: 167.

[21] Wen Y, He K, Zhu YJ, et al. Expanded graphite as superior anode for sodium-ion batteries. Nat Commun 2014, 5: 4033.

[22] Bianco A, Cheng HM, Enoki T, et al. All in the graphene family-A recommended nomenclature for two-dimensional carbon materials. Carbon 2013, 65: 1-6.

[23] Papageorgiou DG, Kinloch IA, Young RJ. Mechanical properties of graphene and graphene-based nanocomposites. Prog Mater Sci 2017, 90: 75-127.

[24] Yi M, Shen ZG. A review on mechanical exfoliation for the scalable production of graphene. $J$ Mater Chem A 2015, 3: 11700-11715.

[25] Bracamonte MV, Lacconi GI, Urreta SE, et al. On the nature of defects in liquid-phase exfoliated graphene. $J$ Phys Chem C 2014, 118: 15455-15459.

[26] Porwal H, Saggar R, Tatarko P, et al. Effect of lateral size of graphene nano-sheets on the mechanical properties and machinability of alumina nano-composites. Ceram Int 2016, 42: 7533-7542.

[27] Porwal H, Tatarko P, Grasso S, et al. Graphene reinforced alumina nano-composites. Carbon 2013, 64: 359-369.

[28] Zhao GK, Li XM, Huang MR, et al. The physics and chemistry of graphene-on-surfaces. Chem Soc Rev 2017, 46: 4417-4449.

[29] Wu ZS, Ren WC, Gao LB, et al. Synthesis of graphene sheets with high electrical conductivity and good thermal stability by hydrogen arc discharge exfoliation. ACS Nano 2009, 3: 411-417.

[30] Dreyer DR, Park S, Bielawski CW, et al. The chemistry of graphene oxide. Chem Soc Rev 2010, 39: 228-240.

[31] Brodie BC. XIII. On the atomic weight of graphite. Phil Trans $R$ Soc 1859, 149: 249-259.

[32] Staudenmaier L. Verfahren zur darstellung der graphitsäure. Ber Dtsch Chem Ges 1898, 31: 1481-1487.

[33] Hummers WSJr, Offeman RE. Preparation of graphitic oxide. J Am Chem Soc 1958, 80: 1339.

[34] Chen F, Jin DQ, Tyeb K, et al. Field assisted sintering of graphene reinforced zirconia ceramics. Ceram Int 2015, 41: 6113-6116.

[35] Vu DT, Han YH, Lee DY. Spark plasma sintered $\mathrm{ZrO}_{2}$ :
Effect of sintering temperature and the addition of graphene nano-platelets on mechanical properties. Sci Adv Mater 2016, 8: 408-413.

[36] Shin JH, Hong SH. Fabrication and properties of reduced graphene oxide reinforced yttria-stabilized zirconia composite ceramics. J Eur Ceram Soc 2014, 34: 1297-1302.

[37] Belmonte M, Nistal A, Boutbien P, et al. Toughened and strengthened silicon carbide ceramics by adding graphene-based fillers. Scr Mater 2016, 113: 127-130.

[38] Viinikanoja A, Kauppila J, Damlin P, et al. In situ FTIR and Raman spectroelectrochemical characterization of graphene oxide upon electrochemical reduction in organic solvents. Phys Chem Chem Phys 2015, 17: 12115-12123.

[39] Krishnamoorthy K, Veerapandian M, Mohan R, et al. Investigation of Raman and photoluminescence studies of reduced graphene oxide sheets. Appl Phys A 2012, 106: 501-506.

[40] Kudin KN, Ozbas B, Schniepp HC, et al. Raman spectra of graphite oxide and functionalized graphene sheets. Nano Lett 2008, 8: 36-41.

[41] Ferrari AC, Meyer JC, Scardaci V, et al. Raman spectrum of graphene and graphene layers. Phys Rev Lett 2006, 97 : 187401.

[42] Ayissi S, Charpentier PA, Farhangi N, et al. Interaction of titanium oxide nanostructures with graphene and functionalized graphene nanoribbons: A DFT study. $J$ Phys Chem C 2013, 117: 25424-25432.

[43] Xu L, Huang WQ, Wang LL, et al. Interfacial interactions of semiconductor with graphene and reduced graphene oxide: $\mathrm{CeO}_{2}$ as a case study. ACS Appl Mater Interfaces 2014, 6: 20350-20357.

[44] Yakovlev AV, Finaenov AI, Zabud'kov SL, et al. Thermally expanded graphite: Synthesis, properties, and prospects for use. Russ J Appl Chem 2006, 79: 1741-1751.

[45] Liu X, Fan YC, Li JL, et al. Preparation and mechanical properties of graphene nanosheet reinforced alumina composites. Adv Eng Mater 2015, 17: 28-35.

[46] Zhu TB, Li YW, Luo M, et al. Microstructure and mechanical properties of $\mathrm{MgO}-\mathrm{C}$ refractories containing graphite oxide nanosheets (GONs). Ceram Int 2013, 39: 3017-3025.

[47] Qing YC, Wen QL, Luo F, et al. Temperature dependence of the electromagnetic properties of graphene nanosheet reinforced alumina ceramics in the X-band. J Mater Chem C 2016, 4: 4853-4862.

[48] Alexander R, Murthy T, Ravikanth KV, et al. Effect of graphene nano-platelet reinforcement on the mechanical properties of hot pressed boron carbide based composite. Ceram Int 2018, 44: 9830-9838.

[49] Zhang YB, Xiao GC, Yi MD, et al. Effect of graphene orientation on microstructure and mechanical properties of silicon nitride ceramics. Process Appl Ceram 2018, 12: 27-35.

[50] Liu J, Yan HX, Jiang K. Mechanical properties of 
graphene platelet-reinforced alumina ceramic composites. Ceram Int 2013, 39: 6215-6221.

[51] Fan YC, Estili M, Igarashi G, et al. The effect of homogeneously dispersed few-layer graphene on microstructure and mechanical properties of $\mathrm{Al}_{2} \mathrm{O}_{3}$ nanocomposites. J Eur Ceram Soc 2014, 34: 443-451.

[52] Fan YC, Igarashi G, Jiang W, et al. Highly strain tolerant and tough ceramic composite by incorporation of graphene. Carbon 2015, 90: 274-283.

[53] Li M, Wang WM, He QL, et al. Reduced-graphene-oxidereinforced boron carbide ceramics fabricated by spark plasma sintering from powder mixtures obtained by heterogeneous co-precipitation. Ceram Int 2019, 45: 16496-16503.

[54] $\mathrm{Hu} \mathrm{LX}$, Wang WM, He QL, et al. Preparation and characterization of reduced graphene oxide-reinforced boron carbide ceramics by self-assembly polymerization and spark plasma sintering. $J$ Eur Ceram Soc 2020, 40: 612-621.

[55] Pierin G, Grotta C, Colombo P, et al. Direct ink writing of micrometric SiOC ceramic structures using a preceramic polymer. J Eur Ceram Soc 2016, 36: 1589-1594.

[56] Zhang QQ, Lin D, Deng BW, et al. Flyweight, superelastic, electrically conductive, and flame-retardant 3D multi-nanolayer graphene/ceramic metamaterial. $A d v$ Mater 2017, 29: 1605506.

[57] Luo CJ, Jiao T, Gu JW, et al. Graphene shield by SiBCN ceramic: A promising high-temperature electromagnetic wave-absorbing material with oxidation resistance. ACS Appl Mater Interfaces 2018, 10: 39307-39318.

[58] Han MK, Yin XW, Duan WY, et al. Hierarchical graphene/SiC nanowire networks in polymer-derived ceramics with enhanced electromagnetic wave absorbing capability. J Eur Ceram Soc 2016, 36: 2695-2703.

[59] Song CK, Cheng LF, Liu YS, et al. Microstructure and electromagnetic wave absorption properties of RGO-SiBCN composites via PDC technology. Ceram Int 2018, 44: 18759-18769.

[60] Liu XM, Yu ZJ, Ishikawa R, et al. Single-source-precursor derived $\mathrm{RGO} / \mathrm{CNTs}-\mathrm{SiCN}$ ceramic nanocomposite with ultra-high electromagnetic shielding effectiveness. Acta Mater 2017, 130: 83-93.

[61] Liu XM, Yu ZJ, Ishikawa R, et al. Single-source-precursor synthesis and electromagnetic properties of novel RGO-SiCN ceramic nanocomposites. $J$ Mater Chem C 2017, 5: 7950-7960.

[62] Qing YC, Wen QL, Luo F, et al. Graphene nanosheets/ $\mathrm{BaTiO}_{3}$ ceramics as highly efficient electromagnetic interference shielding materials in the X-band. $J$ Mater Chem C 2016, 4: 371-375.

[63] Zou HR, Zhang YP, Liu LQ, et al. The toughening mechanism and mechanical properties of graphene-reinforced zirconia ceramics by microwave sintering. Adv Appl Ceram 2018, 117: 420-426.

[64] Markandan K, Chin JK, Tan MTT. Recent progress in graphene based ceramic composites: A review. $J$ Mater Res 2017, 32: 84-106.

[65] Zhang Z, Duan XM, Qiu BF, et al. Preparation and anisotropic properties of textured structural ceramics: A review. J Adv Ceram 2019, 8: 289-332.

[66] Maros B M, Németh AK, Károly Z, et al. Tribological characterisation of silicon nitride/multilayer graphene nanocomposites produced by HIP and SPS technology. Tribol Int 2016, 93: 269-281.

[67] Liu LX, Wang Y, Li XH, et al. Enhancing toughness in boron carbide with reduced graphene oxide. J Am Ceram Soc 2016, 99: 257-264.

[68] Chen C, Pan LM, Jiang SC, et al. Electrical conductivity, dielectric and microwave absorption properties of graphene nanosheets/magnesia composites. J Eur Ceram Soc 2018, 38: $1639-1646$.

[69] Ru JH, Fan YC, Zhou WW, et al. Electrically conductive and mechanically strong graphene/mullite ceramic composites for high-performance electromagnetic interference shielding. ACS Appl Mater Interfaces 2018, 10: 39245-39256.

[70] Kim W, Oh HS, Shon IJ. The effect of graphene reinforcement on the mechanical properties of $\mathrm{Al}_{2} \mathrm{O}_{3}$ ceramics rapidly sintered by high-frequency induction heating. Int J Refract Met Hard Mater 2015, 48: 376-381.

[71] Shon IJ. Enhanced mechanical properties of the nanostructured AlN-graphene composites rapidly sintered by high-frequency induction heating. Ceram Int 2016, 42: 16336-16342.

[72] Antou G, Guyot P, Pradeilles N, et al. Identification of densification mechanisms of pressure-assisted sintering: Application to hot pressing and spark plasma sintering of alumina. J Mater Sci 2015, 50: 2327-2336.

[73] Zhou MY, Zhong J, Zhao J, et al. Microstructures and properties of $\mathrm{Si}_{3} \mathrm{~N}_{4} / \mathrm{TiN}$ composites sintered by hot pressing and spark plasma sintering. Mater Res Bull 2013, 48: $1927-1933$.

[74] Olevsky E, Froyen L. Constitutive modeling of spark-plasma sintering of conductive materials. Scr Mater 2006, 55: 1175-1178.

[75] Wu WW, Gui JY, Sai W, et al. The reinforcing effect of graphene nano-platelets on the cryogenic mechanical properties of $\mathrm{GNPs} / \mathrm{Al}_{2} \mathrm{O}_{3}$ composites. $J$ Alloys Compd 2017, 691: 778-785.

[76] Çelik Y, Çelik A, Flahaut E, et al. Anisotropic mechanical and functional properties of graphene-based alumina matrix nanocomposites. J Eur Ceram Soc 2016, 36: 2075-2086.

[77] del Río F, Boado MG, Rama A, et al. A comparative study on different aqueous-phase graphite exfoliation methods for few-layer graphene production and its application in alumina matrix composites. J Eur Ceram Soc 2017, 37: 3681-3693.

[78] Zhang L, Wang Z, Wu JY, et al. Comparison of the homemade and commercial graphene in heightening 
mechanical properties of $\mathrm{Al}_{2} \mathrm{O}_{3}$ ceramic. Ceram Int 2017, 43: 2143-2149.

[79] $\mathrm{Hu} \mathrm{YY}, \mathrm{Xu} \mathrm{CH}$, Xiao GC, et al. Electrostatic self-assembly preparation of reduced graphene oxide-encapsulated alumina nanoparticles with enhanced mechanical properties of alumina nanocomposites. J Eur Ceram Soc 2018, 38: 5122-5133.

[80] Liu J, Yang, Hassanin H, et al. Graphene-alumina nanocomposites with improved mechanical properties for biomedical applications. ACS Appl Mater Interfaces 2016, 8: $2607-2616$.

[81] Meng XL, Xu CH, Xiao GC, et al. Microstructure and anisotropy of mechanical properties of graphene nanoplate toughened $\mathrm{Al}_{2} \mathrm{O}_{3}$-based ceramic composites. Ceram Int 2016, 42: 16090-16095.

[82] Kostecki M, Grybczuk M, Klimczyk P, et al. Structural and mechanical aspects of multilayer graphene addition in alumina matrix composites-validation of computer simulation model. J Eur Ceram Soc 2016, 36: 4171-4179.

[83] Ahmad I, Islam M, Subhani $\mathrm{T}$, et al. Toughness enhancement in graphene nanoplatelet/SiC reinforced $\mathrm{Al}_{2} \mathrm{O}_{3}$ ceramic hybrid nanocomposites. Nanotechnology 2016, 27: 425704.

[84] Liang L, Li Y. Preparation method of oriented graphene/ alumina composite ceramic. China patent $110143810 \mathrm{~A}$, Aug. 2019.

[85] Liang L. Controllable preparation and toughening mechanism of graphene/alumina composites. M.S. Thesis. Harbin, China: Harbin Institute of Technology, 2019.

[86] Boniecki M, Gołębiewski $\mathrm{P}$, Wesołowski W, et al. Alumina/zirconia composites toughened by the addition of graphene flakes. Ceram Int 2017, 43: 10066-10070.

[87] Rincón A, Moreno R, Chinelatto ASA, et al. Effect of graphene and $\mathrm{CNFs}$ addition on the mechanical and electrical properties of dense alumina-toughened zirconia composites. Ceram Int 2016, 42: 1105-1113.

[88] Li S, Xie ZP, Zhang YM, et al. Enhanced toughness of zirconia ceramics with graphene platelets consolidated by spark plasma sintering. Int J Appl Ceram Technol 2017, 14: 1062-1068.

[89] Ramesh S, Khan MM, Alexander Chee HC, et al. Sintering behaviour and properties of graphene oxide-doped Y-TZP ceramics. Ceram Int 2016, 42: 17620-17625.

[90] Belmonte M, Miranzo P, Osendi MI. Contact damage resistant $\mathrm{SiC} /$ graphene nanofiller composites. J Eur Ceram Soc 2018, 38: 41-45.

[91] Román-Manso B, Sánchez-González E, Ortiz AL, et al. Contact-mechanical properties at pre-creep temperatures of fine-grained graphene/SiC composites prepared in situ by spark-plasma sintering. J Eur Ceram Soc 2014, 34: 1433-1438.

[92] Sedlák R, KovalLíková A, Girman V, et al. Fracture characteristics of $\mathrm{SiC} /$ graphene platelet composites. J Eur Ceram Soc 2017, 37: 4307-4314.

[93] Kun P, Tapasztó O, Wéber F, et al. Determination of structural and mechanical properties of multilayer graphene added silicon nitride-based composites. Ceram Int 2012, 38: 211-216.

[94] Rutkowski P, Stobierski L, Zientara D, et al. The influence of the graphene additive on mechanical properties and wear of hot-pressed $\mathrm{Si}_{3} \mathrm{~N}_{4}$ matrix composites. J Eur Ceram Soc 2015, 35: 87-94.

[95] Sedlák R, Kovalčíková A, Múdra E, et al. Boron carbide/graphene platelet ceramics with improved fracture toughness and electrical conductivity. $J$ Eur Ceram Soc 2017, 37: 3773-3780.

[96] Kovalčíková A, Sedlák R, Rutkowski P, et al. Mechanical properties of boron carbide+graphene platelet composites. Ceram Int 2016, 42: 2094-2098.

[97] Yun C, Feng YB, Qiu T, et al. Mechanical, electrical, and thermal properties of graphene nanosheet/aluminum nitride composites. Ceram Int 2015, 41: 8643-8649.

[98] Mehrali M, Moghaddam E, Seyed Shirazi SF, et al. Mechanical and in vitro biological performance of graphene nanoplatelets reinforced calcium silicate composite. PLoS One 2014, 9: e106802.

[99] Li ZL, Zhao J, Sun JL, et al. Reinforcing effect of graphene on the mechanical properties of $\mathrm{Al}_{2} \mathrm{O}_{3} / \mathrm{TiC}$ ceramics. Int J Miner Metall Mater 2017, 24: 1403-1411.

[100] Mukherjee B, Asiq Rahman OS, Islam A, et al. Plasma sprayed carbon nanotube and graphene nanoplatelets reinforced alumina hybrid composite coating with outstanding toughness. J Alloys Compd 2017, 727: 658-670.

[101] Akin I, Kaya O. Microstructures and properties of silicon carbide- and graphene nanoplatelet-reinforced titanium diboride composites. J Alloys Compd 2017, 729: 949-959.

[102] Thomas T, Zhang C, Sahu A, et al. Effect of graphene reinforcement on the mechanical properties of $\mathrm{Ti}_{2} \mathrm{AlC}$ ceramic fabricated by spark plasma sintering. Mater $\mathrm{Sci}$ Eng: A 2018, 728: 45-53.

[103] Sharma N, Alam SN, Ray BC, et al. Silica-graphene nanoplatelets and silica-MWCNT composites: Microstructure and mechanical properties. Diam Relat Mater 2018, 87: 186-201.

[104] del Corro E, Taravillo M, Baonza VG. Nonlinear strain effects in double-resonance Raman bands of graphite, graphene, and related materials. Phys Rev B 2012, 85: 033407.

[105] Fan YC, Wang LJ, Li JL, et al. Preparation and electrical properties of graphene nanosheet $/ \mathrm{Al}_{2} \mathrm{O}_{3}$ composites. Carbon 2010, 48: 1743-1749.

[106] Ramirez C, Figueiredo FM, Miranzo P, et al. Graphene nanoplatelet/silicon nitride composites with high electrical conductivity. Carbon 2012, 50: 3607-3615.

[107] Miranzo P, Belmonte M, Osendi MI. From bulk to cellular structures: A review on ceramic/graphene filler composites. $J$ Eur Ceram Soc 2017, 37: 3649-3672.

[108] Singh K, Ohlan A, Pham VH, et al. Nanostructured 
graphene $/ \mathrm{Fe}_{3} \mathrm{O}_{4}$ incorporated polyaniline as a high performance shield against electromagnetic pollution. Nanoscale 2013, 5: 2411.

[109] Joshi A, Datar S. Carbon nanostructure composite for electromagnetic interference shielding. Pramana 2015, 84: 1099-1116.

[110] Han MK, Yin XW, Hou ZX, et al. Flexible and thermostable graphene/SiC nanowire foam composites with tunable electromagnetic wave absorption properties. ACS Appl Mater Interfaces 2017, 9: 11803-11810.

[111] Xu DW, Xiong XH, Chen P, et al. Superior corrosionresistant 3D porous magnetic graphene foam-ferrite nanocomposite with tunable electromagnetic wave absorption properties. J Magn Magn Mater 2019, 469: 428-436.

[112] Agarwal PR, Kumar R, Kumari S, et al. Three-dimensional and highly ordered porous carbon- $\mathrm{MnO}_{2}$ composite foam for excellent electromagnetic interference shielding efficiency. RSC Adv 2016, 6: 100713-100722.

[113] Yin XW, Kong L, Zhang LT, et al. Electromagnetic properties of $\mathrm{Si}-\mathrm{C}-\mathrm{N}$ based ceramics and composites. Int Mater Rev 2014, 59: 326-355.

[114] Chen MX, Zhu Y, Pan YB, et al. Gradient multilayer structural design of $\mathrm{CNTs} / \mathrm{SiO}_{2}$ composites for improving microwave absorbing properties. Mater Des 2011, 32: 3013-3016.

[115] Lv H, Guo YH, Yang ZH, et al. A brief introduction to the fabrication and synthesis of graphene based composites for the realization of electromagnetic absorbing materials. J Mater Chem C 2017, 5: 491-512.

[116] Wen B, Cao MS, Lu MM, et al. Reduced graphene oxides: Light-weight and high-efficiency electromagnetic interference shielding at elevated temperatures. $A d v$ Mater 2014, 26: 3484-3489.

[117] Li M, Yin XW, Chen LQ, et al. Dielectric and electromagnetic wave absorption properties of reduced graphene oxide/barium aluminosilicate glass-ceramic composites. Ceram Int 2016, 42: 7099-7106.

[118] Ye F, Song Q, Zhang ZC, et al. Direct growth of edge-rich graphene with tunable dielectric properties in porous $\mathrm{Si}_{3} \mathrm{~N}_{4}$ ceramic for broadband high-performance microwave absorption. Adv Funct Mater 2018, 28: 1707205.

[119] Cao WQ, Wang XX, Yuan J, et al. Temperature dependent microwave absorption of ultrathin graphene composites. $J$ Mater Chem C 2015, 3: 10017-10022.

[120] Wang CH, Liu YS, Zhao MX, et al. Three-dimensional graphene/SiBCN composites for high-performance electromagnetic interference shielding. Ceram Int 2018, 44: 22830-22839.

[121] Li ZB, Wang YG. Preparation of polymer-derived graphene-like carbon-silicon carbide nanocomposites as electromagnetic interference shielding material for high temperature applications. J Alloys Compd 2017, 709: 313-321.

[122] Wang CH, Liu YS, Zhao MX, et al. Effects of upgrading temperature on electromagnetic shielding properties of three-dimensional graphene/SiBCN/SiC ceramic composites. Ceram Int 2019, 45: 21278-21285.

[123] Cao MS, Han C, Wang XX, et al. Graphene nanohybrids: Excellent electromagnetic properties for the absorbing and shielding of electromagnetic waves. J Mater Chem C 2018, 6: 4586-4602.

[124] Ahmad I, Parvez S, Saeed K. Interfacial investigation, mechanical performance and thermal permanence of the inductively hot-pressed alumina ceramic hybrid nanocomposites reinforced by silicon carbide and multilayer graphene. Int J Refract Met Hard Mater 2019, 81: 49-57.

[125] Li QS, Zhang YJ, Gong HY, et al. Effects of graphene on the thermal conductivity of pressureless-sintered $\mathrm{SiC}$ ceramics. Ceram Int 2015, 41: 13547-13552.

[126] Xia HY, Zhang X, Shi ZQ, et al. Mechanical and thermal properties of reduced graphene oxide reinforced aluminum nitride ceramic composites. Mater Sci Eng: A 2015, 639: 29-36.

[127] Chen C, Pan LM, Li XY, et al. Mechanical and thermal properties of graphene nanosheets/magnesia composites. Ceram Int 2017, 43: 10377-10385.

[128] Lin CJ, Lin IC, Tuan WH. Effect of graphene concentration on thermal properties of alumina-graphene composites formed using spark plasma sintering. J Mater Sci 2017, 52: 1759-1766.

[129] Yin R, Zhang YB, Zhao W, et al. Graphene platelets/ aluminium nitride metacomposites with double percolation property of thermal and electrical conductivity. $J$ Eur Ceram Soc 2018, 38: 4701-4706.

[130] Román-Manso B, Chevillotte Y, Osendi MI, et al. Thermal conductivity of silicon carbide composites with highly oriented graphene nanoplatelets. J Eur Ceram Soc 2016, 36: 3987-3993.

[131] Cinar A, Baskut S, Seyhan AT, et al. Tailoring the properties of spark plasma sintered SiAlON containing graphene nanoplatelets by using different exfoliation and size reduction techniques: Anisotropic mechanical and thermal properties. J Eur Ceram Soc 2018, 38: 1299-1310.

[132] Thomas T, Zhang C, Nautiyal P, et al. 3D graphene foam reinforced low-temperature ceramic with multifunctional mechanical, electrical, and thermal properties. $A d v$ Eng Mater 2019, 21: 1900085.

[133] Fan JM, Hui S, Bailey TP, et al. Ultralow thermal conductivity in graphene-silica porous ceramics with a special saucer structure of graphene aerogels. $J$ Mater Chem A 2019, 7: 1574-1584.

[134] Zhou M, Lin TQ, Huang FQ, et al. Highly conductive porous graphene/ceramic composites for heat transfer and thermal energy storage. Adv Funct Mater 2013, 23: 2263-2269.

[135] Kocjan A, Schmidt R, Lazar A, et al. In situ generation of 3D graphene-like networks from cellulose nanofibres in sintered ceramics. Nanoscale 2018, 10: 10488-10497. 
[136] Wu C, Li J, Fan YC, et al. The effect of reduced graphene oxide on microstructure and thermoelectric properties of Nb-doped A-site-deficient $\mathrm{SrTiO}_{3}$ ceramics. J Alloys Compd 2019, 786: 884-893.

Open Access This article is licensed under a Creative Commons Attribution 4.0 International License, which permits use, sharing, adaptation, distribution and reproduction in any medium or format, as long as you give appropriate credit to the original author(s) and the source, provide a link to the Creative
Commons licence, and indicate if changes were made.

The images or other third party material in this article are included in the article's Creative Commons licence, unless indicated otherwise in a credit line to the material. If material is not included in the article's Creative Commons licence and your intended use is not permitted by statutory regulation or exceeds the permitted use, you will need to obtain permission directly from the copyright holder.

To view a copy of this licence, visit http://creativecommons.org/licenses/by/4.0/. 